\section{Approach to the postnatal sonographic evaluation of prenatally detected abdominopelvic cysts}

\author{
Bernadette Wambui Muthee, Heather J. Bray \\ Department of Radiology, British Columbia Children's Hospital, University of British \\ Columbia, Vancouver, BC, Canada
}

Prenatally detected abdominal and pelvic masses are commonly cystic in morphology and usually seen on mid-trimester sonography. Sonography is the favored imaging modality for the postnatal evaluation of these lesions in newborns, given its availability, low cost, lack of ionizing radiation, lack of sedation, and high spatial resolution in small patients. The differential diagnosis of abdominopelvic cystic masses in newborns is broad given that they can arise from many organs and may have overlapping features on imaging. This article illustrates an approach to the postnatal sonographic evaluation of prenatally detected cystic abdominal and pelvic masses based on their anatomic location and distinctive sonographic characteristics, which can aid in an accurate diagnosis and guide appropriate management.

Keywords: Sonography; Abdomen; Pelvis; Cyst; Postnatal evaluation

Key points: Abdominal and pelvic cystic masses in newborns can have overlapping imaging features with broad differential diagnosis. Sonography is the imaging of choice for the postnatal evaluation of these lesions in newborns in order to make an accurate diagnosis and provide appropriate management.

\section{Introduction}

Prenatally detected abdominal and pelvic masses are usually cystic in nature, and are typically seen on second-trimester sonography [1]. These lesions commonly arise from various organs and structures in the abdomen and pelvis [2]. Prenatal sonography is highly sensitive in the detection of abdominopelvic cystic masses, but it lacks specificity and a definitive diagnosis is often challenging [1-3]. Postnatal sonography is often successful in determining the etiology of cystic lesions, occasionally supplemented by magnetic resonance imaging (MRI). Sonography is the preferred modality in this setting, given its portability, lack of ionizing radiation, low cost, and high resolution in small patients. The differential diagnosis of abdominopelvic cystic masses in newborns is broad and can be narrowed by approaching the lesions based on their anatomic location: intraperitoneal, porta hepatis/hepatic, renal/retroperitoneal, splenic, or pelvic. In addition, distinctive sonographic signs, when present, aid in establishing the correct diagnosis [1,3]. An accurate diagnosis is pivotal, as the management of these cystic lesions is highly variable $[2,4]$.

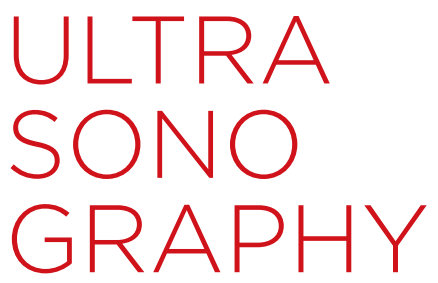

REVIEW ARTICLE

https://doi.org/10.14366/usg.21070 pISSN: 2288-5919 - elSSN: 2288-5943 Ultrasonography 2022;41:53-73

Received: March 25, 2021

Revised: May 21, 2021

Accepted: May 22, 2021

Correspondence to:

Bernadette Wambui Muthee, MBChB, MMed, Rad, Department of Radiology, British Columbia Children's Hospital, University of British Columbia, 4500 Oak St, Vancouver, BC V6H 3N1, Canada

Tel. +1-604-875-2132

Fax. +1-604-875-2367

E-mail: bernadettemuthee@gmail.com

This is an Open Access article distributed under the terms of the Creative Commons Attribution NonCommercial License (http://creativecommons.org/ licenses/by-nc/4.0/) which permits unrestricted noncommercial use, distribution, and reproduction in any medium, provided the original work is properly cited.

Copyright (C) 2022 Korean Society of Ultrasound in Medicine (KSUM)

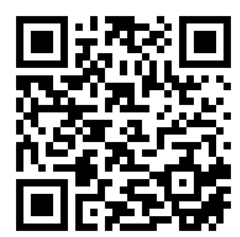

How to cite this article: Muthee BW, Bray HJ. Approach to the postnatal sonographic evaluation of prenatally detected abdominopelvic cysts. Ultrasonography. 2022 Jan;41(1):53-73. 


\section{Intraperitoneal Cystic Masses}

\section{Ovarian Cysts}

Ovarian cysts are the most common abdominal masses found in female neonates [5]. Neonatal ovarian cysts are primarily of follicular origin, presumably arising from disordered folliculogenesis. Excessive stimulation of the fetal ovary by both placental and maternal hormones is thought be a key factor in cyst development [6]. The decrease in hormonal stimulation after birth is associated with spontaneous regression of most small cysts; however, $5-\mathrm{cm}$ diameter or larger cysts are associated with an increased risk of torsion. There is an increased incidence of cysts in infants of mothers with diabetes, toxemia, or rhesus immunization, presumably from hypersecretion of placental human chorionic gonadotropin (hCG) or increased placental permeability to hCG [7].

Neonatal ovarian cysts are categorized as simple or complicated; the latter type occurs in the setting of torsion, and mostly develops antenatally. They are most often unilateral, found anywhere within the peritoneal cavity in neonates, even contralaterally, due to the long neonatal ovarian pedicle. Larger cysts may occupy almost the entire abdomen [5,8-10].

On sonography, simple ovarian cysts are unilocular, round, and anechoic with a thin wall, possibly with a single septum. The "daughter cyst" sign (Figs. 1, 2A), which is highly specific for ovarian cysts, denotes a small round thin-walled anechoic lesion abutting

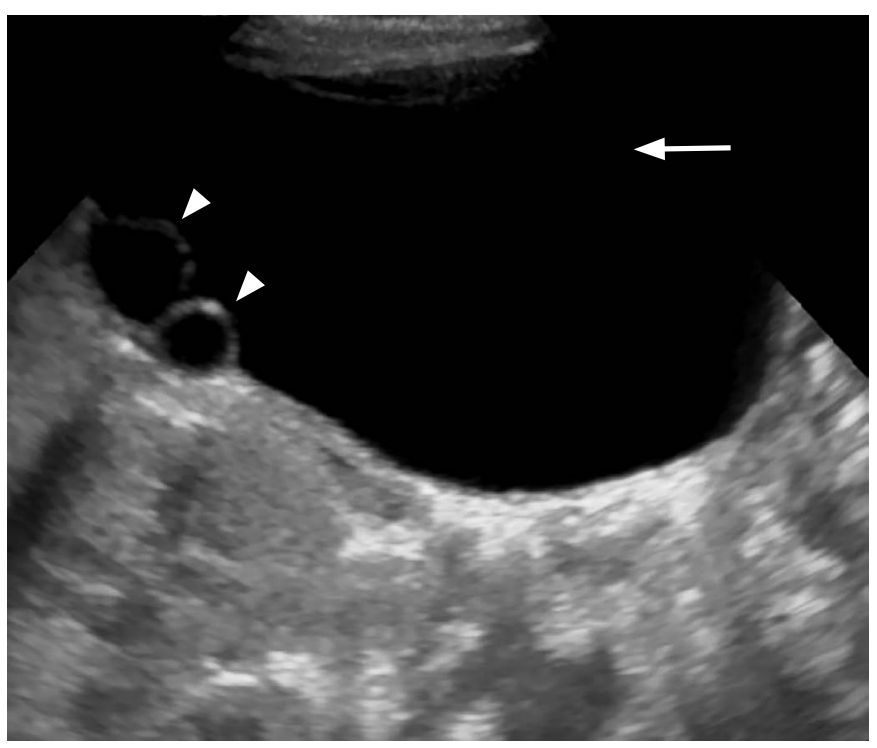

Fig. 1. Simple right ovarian cyst in a 5-week-old baby girl. Postnatal transabdominal grayscale sonography reveals a thin-walled, unilocular, anechoic cyst in the right side of the peritoneal cavity (arrow) consistent with a simple right ovarian cyst. Two small, round, thinwalled anechoic lesions are seen along the inferior margin of the cyst (arrowheads), representing "daughter cysts." the wall of the ovarian cyst [5]. Ovarian torsion has a variable sonographic appearance related to degree of internal hemorrhage, stromal edema, and infarction. Ovarian torsion invariably contains a fluid-debris level, retracting clot, septations, or an area completely filled with echoes producing a solid mass-like appearance (Figs. 2B, $C, 3)$. These complex cysts often have echogenic walls resulting from dystrophic calcification associated with infarction. The absence of internal blood flow on color Doppler evaluation distinguishes solidappearing ovarian torsion from a rare solid intraperitoneal mass $[5,8,11,12]$.

Complications of large ovarian cysts include rupture causing hemorrhagic ascites, peritonitis, or bowel obstruction; thoracic compression resulting in pulmonary hypoplasia; urinary tract obstruction; and incarceration of the ovarian mass within an inguinal hernia [7]. Most small simple ovarian cysts resolve spontaneously. Simple ovarian cysts more than $5 \mathrm{~cm}$ in diameter should be closely monitored with serial ultrasonography. Ovarian torsion merits careful assessment and surgical consultation; if surgical intervention is required, the goal should be to preserve ovarian tissue. Conservative management of complex ovarian cysts has been advocated if the neonate is stable $[5,13,14]$.

\section{Enteric Duplication Cysts}

Enteric duplication cysts are congenital cysts of unknown etiology, arising anywhere along the gastrointestinal tract from the mouth to anus. These cysts are contiguous with a segment of bowel, sharing a muscular layer and arterial blood supply with the adjacent bowel. In the abdomen, they are most common in the ileocecal region, arising on the mesenteric border of the bowel. Most duplication cysts do not communicate with the intestinal lumen, except in the tubular type $[5,15-17]$. Ectopic gastric mucosa can be present in some cases which can present with intralesional hemorrhage [18].

On sonography, most enteric duplication cysts are round, and the tubular type accounts for $20 \%$. They are anechoic with a thick welldefined wall. They have a distinctive "gut signature" or "double wall" sign, which represents the inner hyperechoic mucosal layer and the peripheral hypoechoic muscular wall (Fig. 4). At times, five layers of the gut signature (echogenic mucosa, hypoechoic muscularis mucosa, echogenic submucosa, hypoechoic muscularis propria and echogenic serosa) can be visualized with high-frequency transducers [17]. Rarely, the double wall sign can be seen in ovarian cysts, Meckel diverticula, lymphatic malformations (LMs), or cystic teratomas [18]. Lack of the double wall sign has been reported in duplication cysts, and thought to be related to cyst infection and erosion of the mucosa [17]. Identification of the "split wall" sign, which consists of hypoechoic muscularis propria divided at the point of attachment between the cyst and adjacent bowel, 


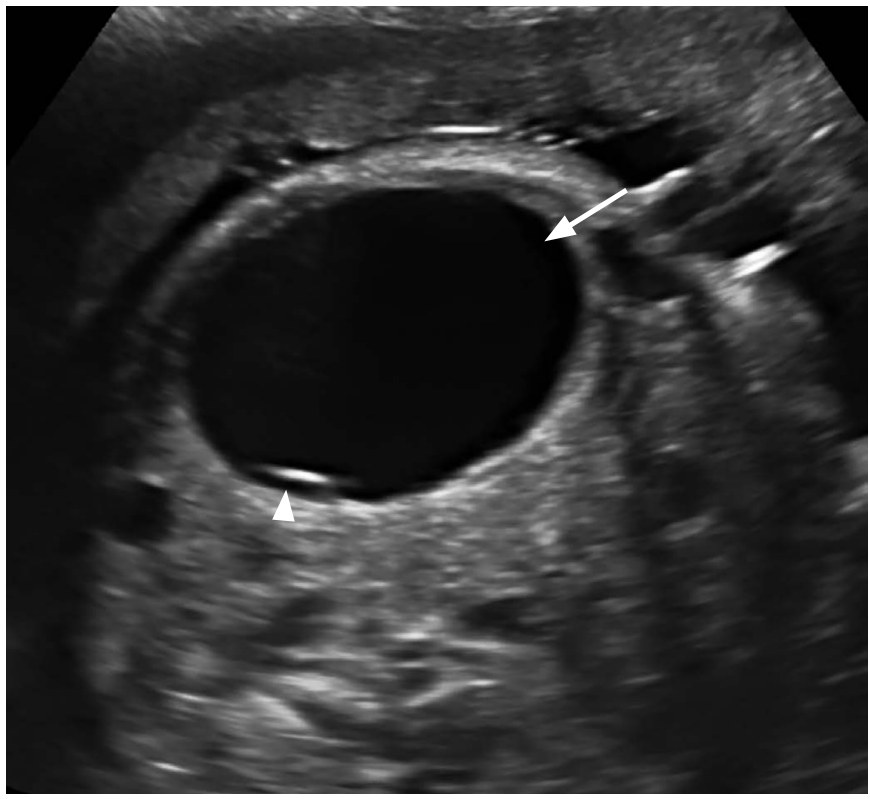

A

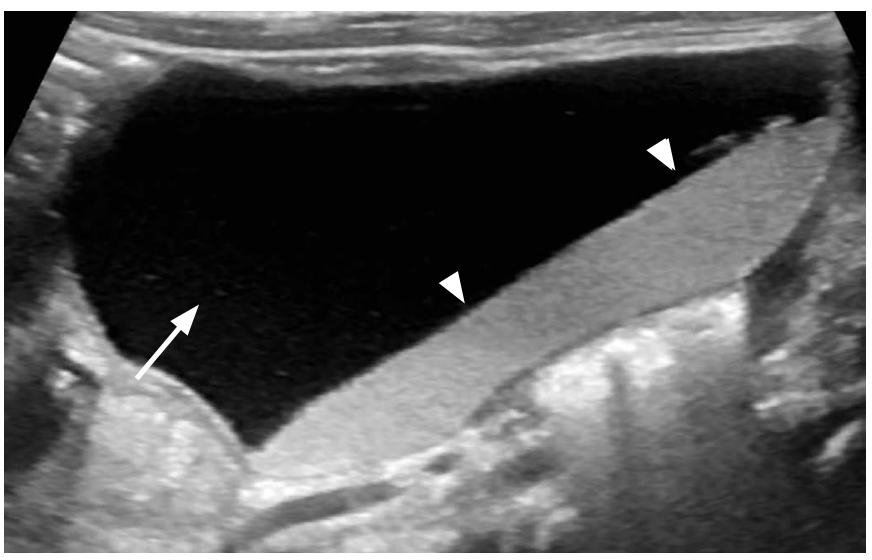

C

or peristalsis of the cyst wall increases specificity in establishing this diagnosis. Septations, internal echoes, or debris related to proteinaceous material, blood products, or infection can be present $[5,17]$. Duplication cysts can lead to intussusception and segmental volvulus; therefore, the treatment is surgical resection $[5,16]$.

\section{Meconium Pseudocysts}

Meconium pseudocysts are rare in neonates, and often coexist with meconium peritonitis, which occurs in the setting of intrauterine bowel perforation. Prenatal bowel perforation can be caused by intestinal atresia, segmental bowel volvulus, meconium ileus, or spontaneous perforation. Leakage of bowel content into the peritoneum causes severe inflammation with adhesions and may result in the development of pseudocysts, reflecting the normal healing process to confine the intraabdominal perforation $[5,10,19]$.

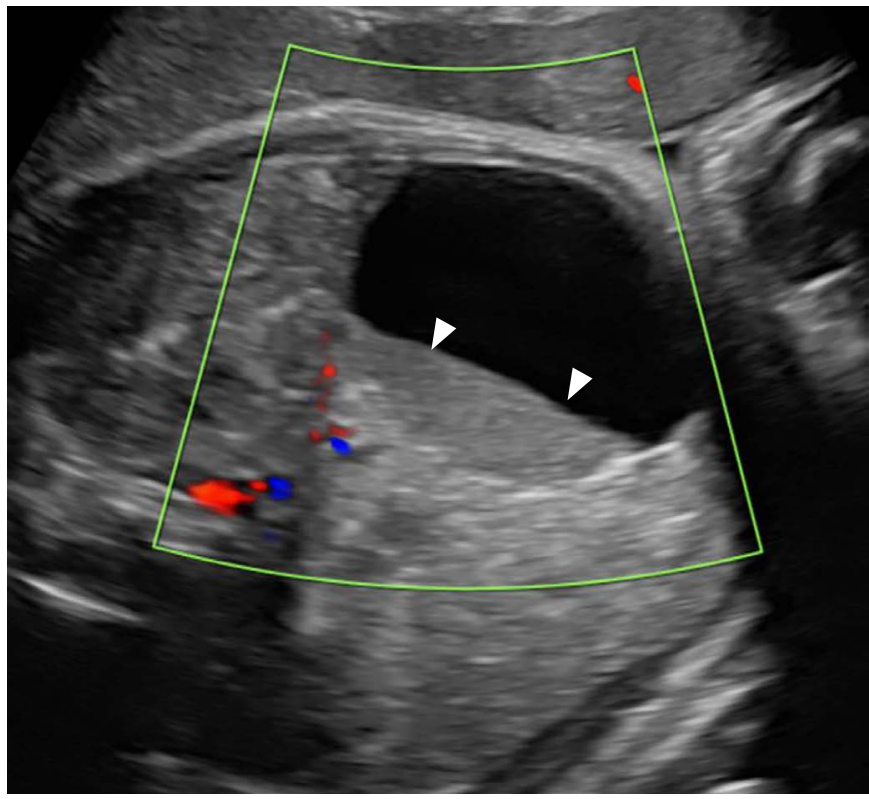

B

Fig. 2. Left ovarian torsion in a 6-week-old baby girl.

A. A prenatal grayscale sonogram at 33 weeks gestational age shows a well-defined anechoic cyst in the left abdomen (arrow) containing a daughter cyst (arrowhead). B. A follow-up prenatal sonogram at 36 weeks gestational age shows echogenic debris layering at the dependent aspect of the cyst (arrowheads), likely related to hemorrhage from ovarian torsion. C. A postnatal longitudinal sonogram shows a cyst (arrow) with fluid-debris layer (arrowheads) and lack of blood flow (not shown).

On sonography, meconium pseudocysts appear cystic, with a thick echogenic calcified wall, variable internal echogenicity, and absent vascularity (Fig. 5). Intraluminal gas can be seen if communication persists between the cyst cavity and the perforated bowel lumen after birth. Dilated bowel loops and ascites may be present [5,1923]. Patients with complicated meconium pseudocysts are managed surgically [24]. In some patients, the perforated bowel spontaneously heals in utero, and the only clue of previous perforation is the finding of peritoneal calcifications [18].

\section{Lymphatic Malformations}

LMs consist of dilated lymphatic channels and spaces with walls lined by mature endothelium. The etiology is unknown; hypotheses include failure of embryonic lymphatic spaces to develop normal connections and drainage into the venous system, and benign 


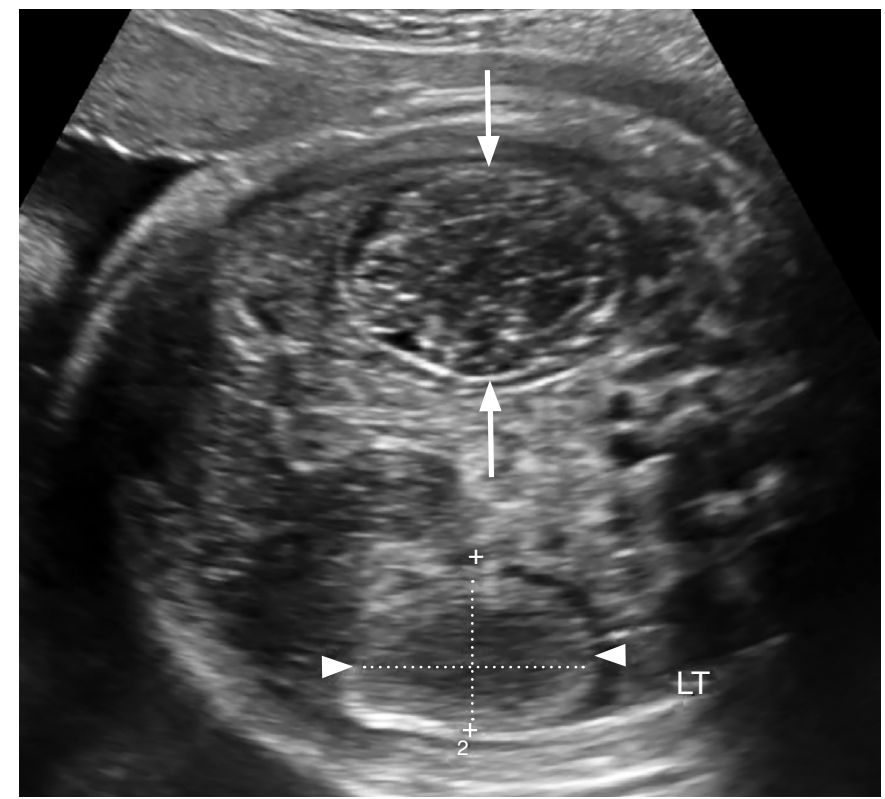

A

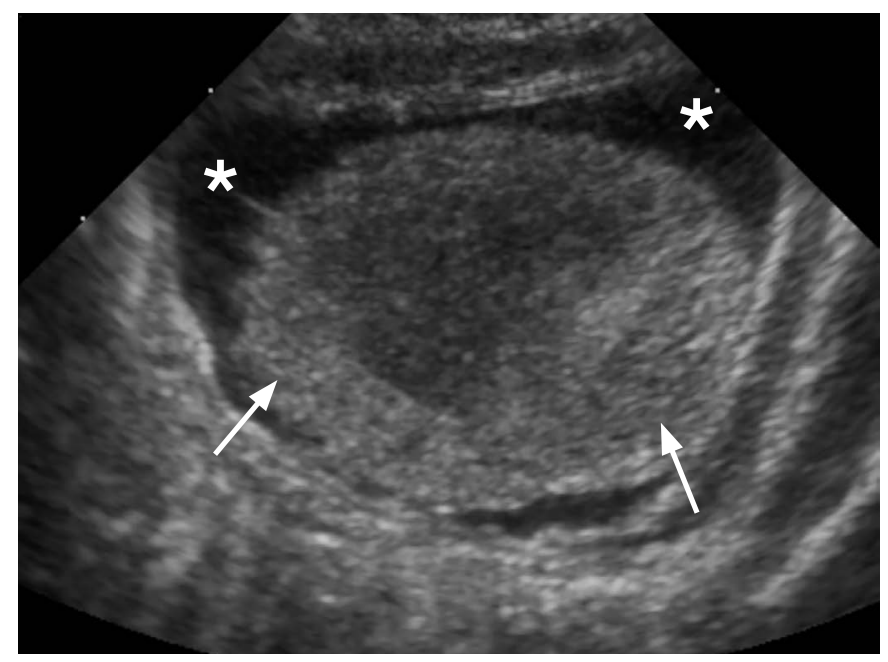

C

proliferation of ectopic lymphatics sequestered from the venous system [25]. LMs have no sex predilection. The head and neck are the commonest sites of involvement, while the abdomen is less frequently involved, and these malformations can arise from small bowel mesentery, omentum, and retroperitoneum [26-28]. They can be asymptomatic or manifest with bowel obstruction, segmental volvulus, hemorrhage, rupture, infection, and torsion of the lesion [29].

LMs consist of cystic structures of variable size. The macrocystic type usually occurs in the abdomen. On sonography, macrocystic lesions appear as thin-walled, unilocular or multilocular anechoic lesions, often with fine septations. Internal echoes or fluid levels

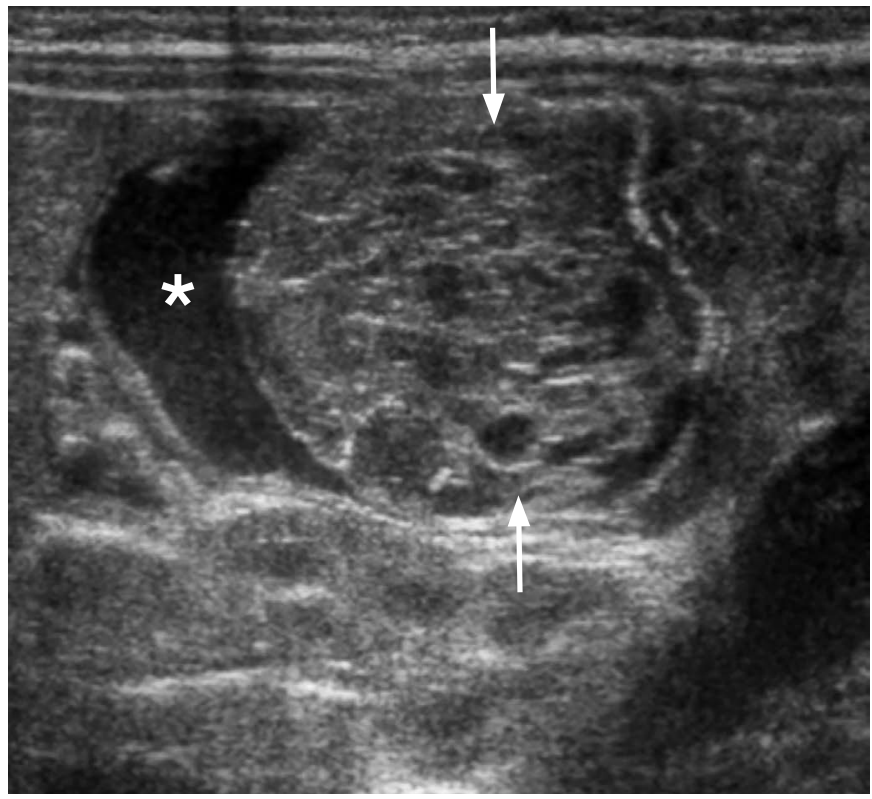

B

Fig. 3. Bilateral ovarian torsion in a 2-week-old baby girl.

A. A prenatal grayscale sonogram in the third trimester shows two well-defined lesions of mixed echogenicity on the right (arrows) and left sides (arrowheads) of the peritoneal cavity. B. The rightsided lesion on a postnatal sonogram has a mesh-like appearance comprising of thick echogenic septa intermixed with small cystic spaces (arrows). A crescentic rim of fluid is seen at the upper aspect of the lesion (asterisk). C. The lesion on the left side has a solid mass-like appearance (arrows) with a surrounding rim of fluid (asterisks).

can be seen related to hemorrhage or infection. On color Doppler imaging, no flow is detected, although septal vascularity can be visualized because they often encase the neighboring mesenteric vessels. Ascites, often chylous, can be present $[18,25,27,30]$. Treatment may include percutaneous sclerotherapy, surgical resection, or a combination of both. The prognosis is generally good, with a low recurrence rate $[26,28]$.

\section{Urachal Cysts}

Urachal cysts are part of a spectrum of congenital anomalies arising from incomplete obliteration of the urachus. The urachus connects the dome of the bladder to the umbilical cord during fetal life and 


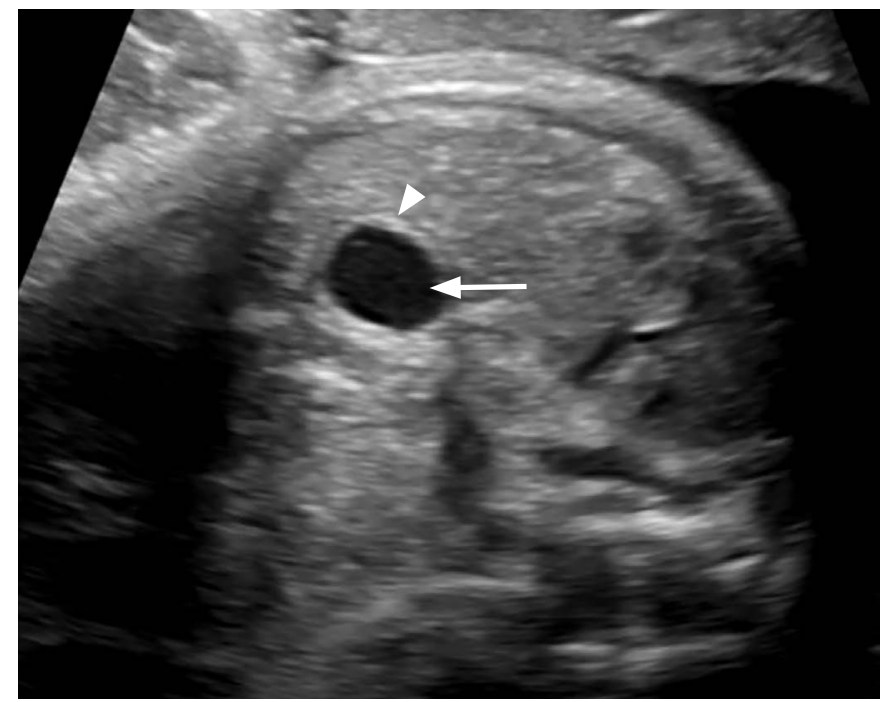

A

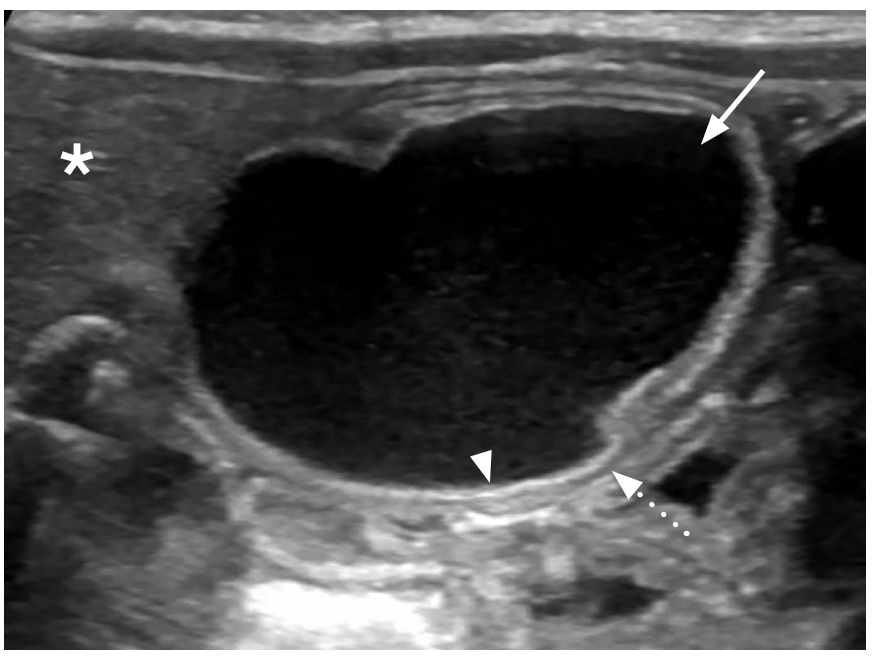

C

is located between the parietal peritoneum and fascia transversalis (space of Retzius). Urachal cysts develop when both the umbilical and bladder end of the urachus are obliterated, but a focal segment remains patent along the course of the urachus. They are rare and more common in males than females, and they can be asymptomatic or manifest clinically with infection.

Uncomplicated urachal cysts appear as simple anechoic lesions on sonography located at the midline behind the lower anterior abdominal wall, in the space of Retzius, between the umbilicus and the bladder. Infected urachal cysts may have a complex sonographic appearance. Complete excision of the urachal remnant is the recommended treatment $[31,32]$.

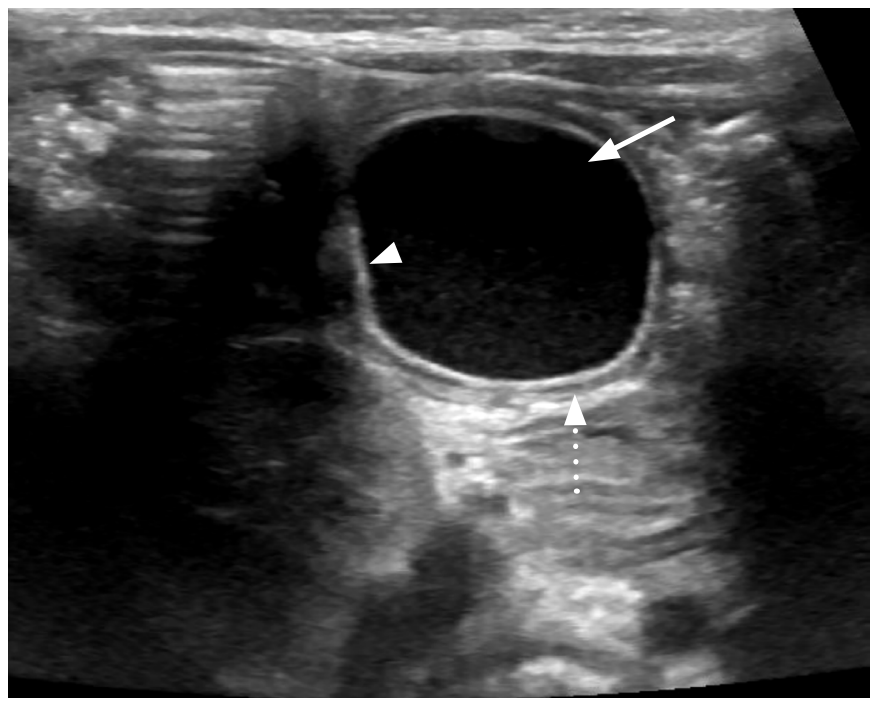

B

Fig. 4. Duplication cyst in a 2-week-old baby boy.

A. A prenatal sonogram at 38 weeks gestational age reveals a well-defined round anechoic cyst on the right side of the abdomen (arrow), with a thick echogenic wall (arrowhead). B, C. Postnatal transverse (B) and longitudinal (C) sonograms show a right-quadrant round cystic mass (arrows), with a distinctive "gut signature sign" comprising an inner hyperechoic mucosal layer (arrowheads) and peripheral hypoechoic muscular wall (dotted arrows). The liver is partially visualized adjacent to the duplication cyst (asterisk).

\section{Porta Hepatis and Hepatic Cystic Masses}

\section{Choledochal Cysts}

Choledochal cysts, which are fusiform or saccular dilatations of the bile ducts, are among the most frequent congenital hepatobiliary anomalies $[33,34]$. The Todani classification system is used to categorize these anomalies into five types based on their etiology, pathogenesis, appearance, and presentation [35]. Type I choledochal cysts are postulated to arise from ductal plate malformation and obstruction of the distal biliary duct and/or reflux of the pancreatic enzymes into the biliary tree, due to an anomalous pancreatobiliary junction [18]. A round or tubular cystic right upper quadrant mass separate from the gallbladder is seen in type I, II, and IV choledochal cysts on sonography (Fig. 6). Type III cysts (choledochocoele) may 


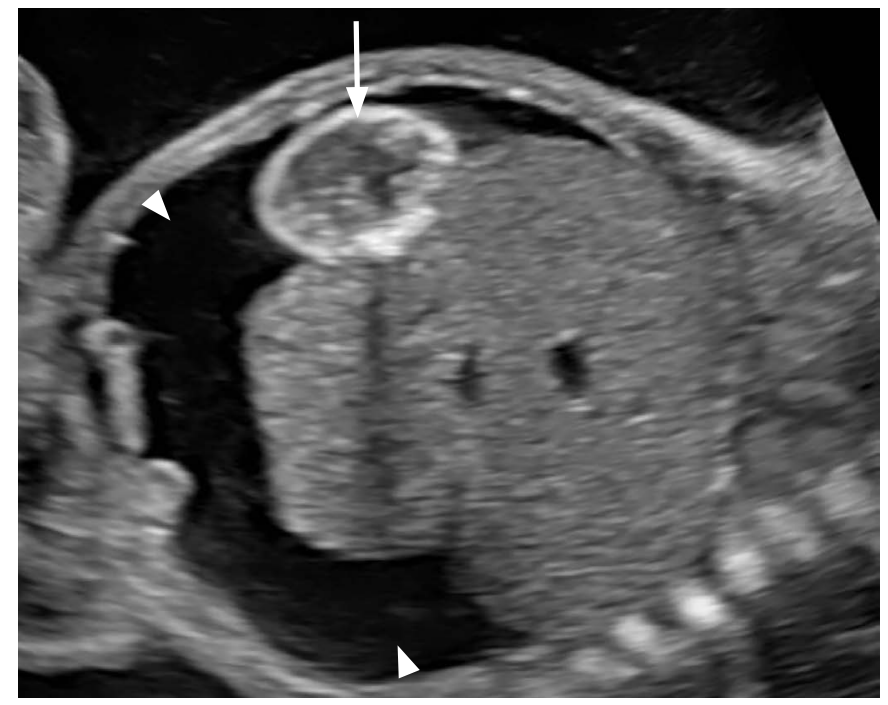

A

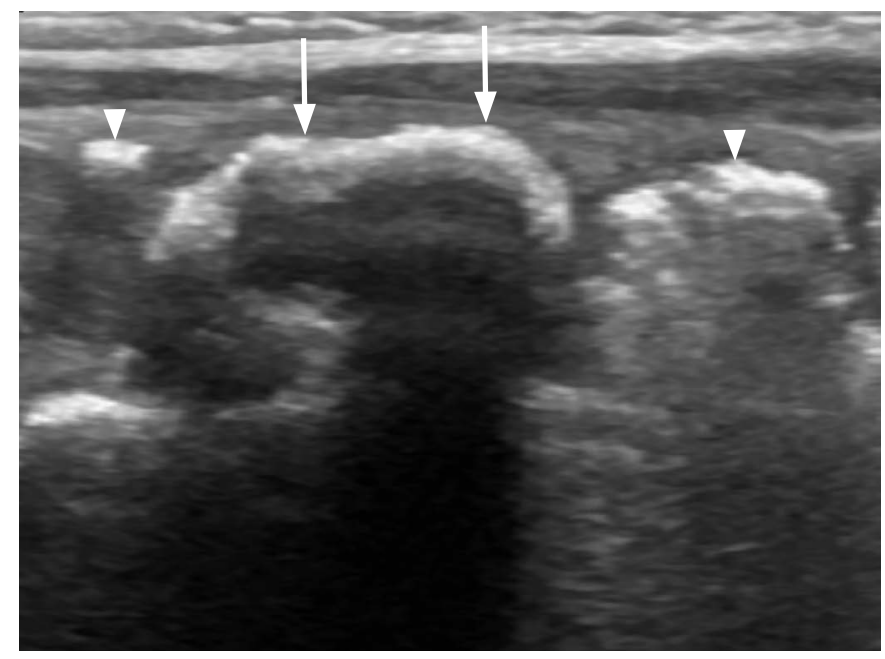

C

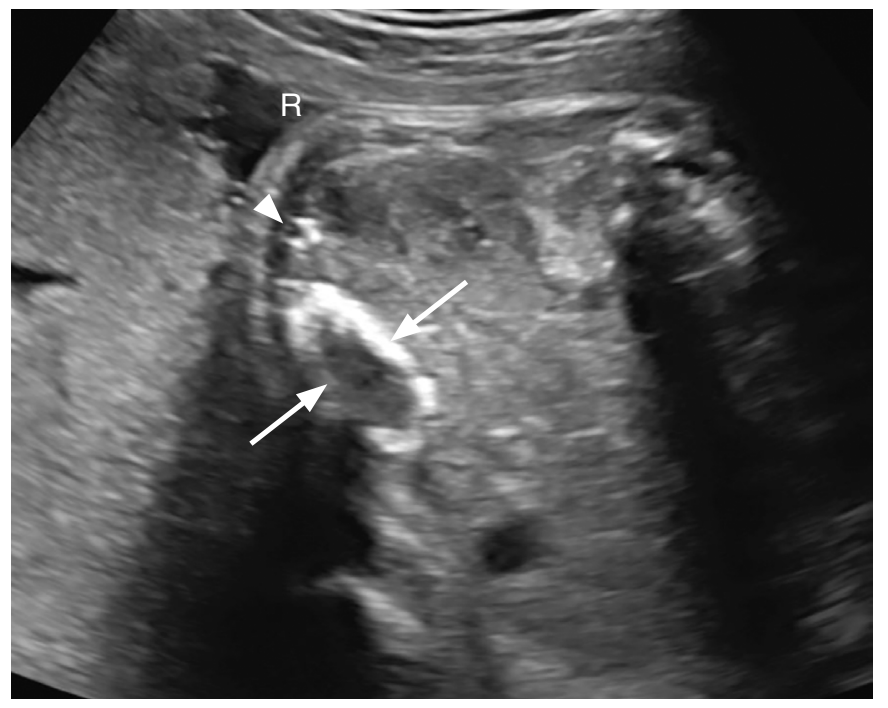

B

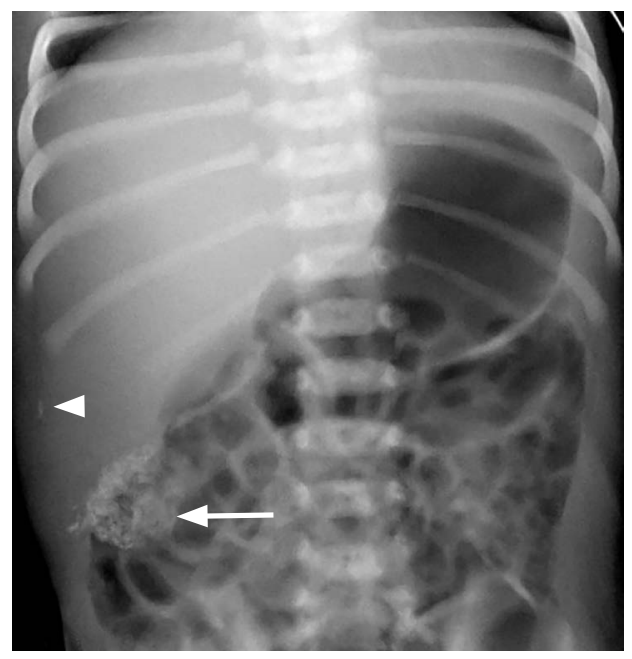

D

Fig. 5. Meconium pseudocyst in a 2-day-old baby boy.

A. A prenatal sonogram at 22 weeks gestational age reveals a round heterogeneous lesion with a thick echogenic calcified wall (arrow), associated with moderate ascites (arrowheads). B. A prenatal follow-up sonogram at 32 weeks gestational age redemonstrates the complex cystic lesion with a thick calcified wall (arrows), and acoustic shadowing. Peritoneal calcifications are visualized (arrowhead) and ascites has resolved. C. A postnatal sonogram reveals a right-quadrant complex cystic mass with a calcified wall (arrows) with acoustic shadowing and peritoneal calcifications (arrowheads). D. A postnatal supine abdominal radiograph shows a rounded calcified mass in the right quadrant (arrow), with accompanying foci of peritoneal calcifications (arrowhead).

cause a mass effect at the ampulla of Vater. Multiple intrahepatic cystic dilatations are seen in type IVA and type $V$ cysts. A normal gallbladder is present, usually adjacent to the dilated common duct (Fig. 6B). Sludge or stones may be seen in the dilated ducts. Choledochal cysts can be differentiated from cystic biliary atresia on sonography on the basis of gallbladder abnormalities, non-dilated bile ducts, smaller cyst (20 mm or less), and lack of sludge or stones, which are characteristic features of biliary atresia [5,34,36-38].
MRI with cholangiopancreatography is the modality of choice to delineate the type of cyst, length of duct involved, presence and location of protein plugs or calculi, and the length of the common channel $[34,36]$. Complications may include calculi, cholangitis, pancreatitis, or cholangiocarcinoma. Surgical excision with hepaticojejunostomy on an elective basis is the definitive treatment $[5,36]$. 


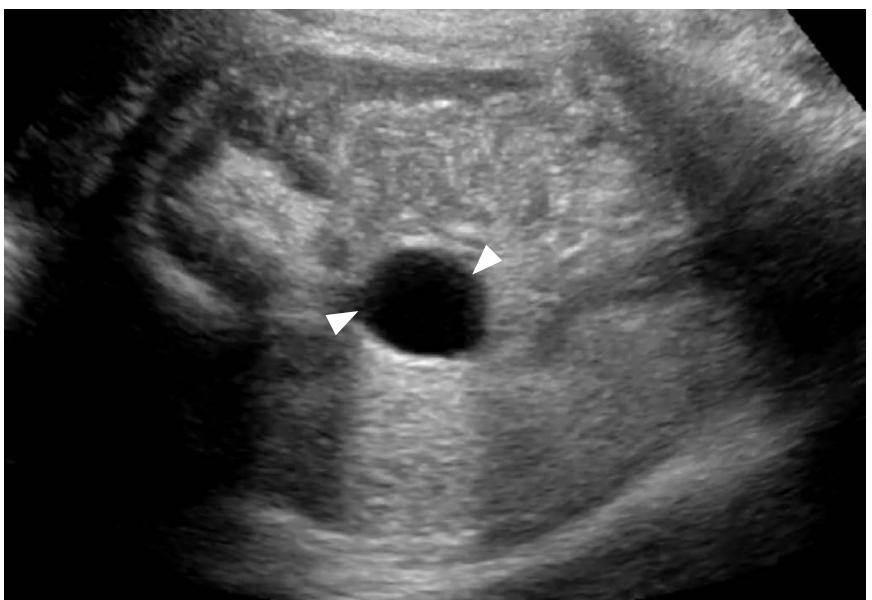

A

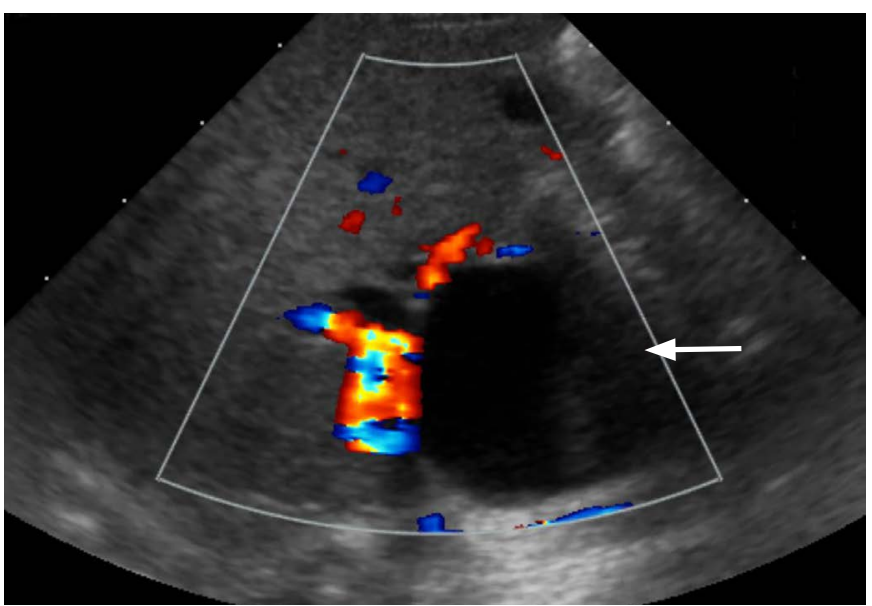

C

\section{Cystic Biliary Atresia}

Cystic biliary atresia is a rare variant of biliary atresia presenting with a cystic structure within the otherwise obliterated extrahepatic bile duct. Biliary atresia is an inflammatory fibro-obliterative disease that affects varying lengths of both intrahepatic and extrahepatic bile ducts. It is a common cause of neonatal cholestasis and a common indication for pediatric liver transplantation. Biliary atresia is more prevalent in Asian populations $[38,39]$. The etiology and pathogenesis of biliary atresia remain unclear, although viral, genetic, toxic, and autoimmune origins have been proposed as possibilities [39]. Most cases of biliary atresia are isolated; however, about 10\%-35\% are associated with congenital anomalies such as situs inversus or polysplenia $[38,40,41]$.

On sonography, cystic biliary atresia presents with a small cyst (20 $\mathrm{mm}$ or less) located at the porta hepatis (Fig. 7A-D). The cyst size tends to remain stable, whereas choledochal cysts may increase in size. Gallbladder abnormalities, such as absent gallbladder, small gallbladder (length $<15 \mathrm{~mm}$ ) or irregular gallbladder wall, and

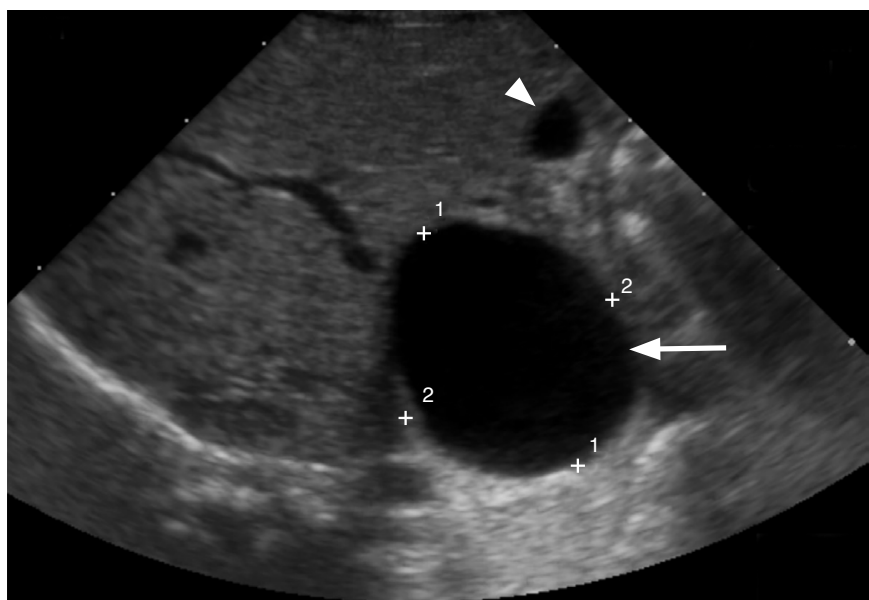

B

Fig. 6. Choledochal cyst in a 4-week-old baby girl.

A. A prenatal third-trimester sonogram shows a well-defined simple cyst in the mid-abdomen (arrowheads). B. A postnatal sonogram shows an anechoic cystic lesion at the porta hepatis (arrow) with a normal-appearing gallbladder (arrowhead). C. No internal flow is present on color Doppler imaging (arrow).

the triangular cord sign ( $>4 \mathrm{~mm}$ of echogenic tissue anterior to the portal vein) are each highly specific for the diagnosis of cystic biliary atresia on sonography (Fig. 7E, F). Absence of the common bile duct, non-dilated bile ducts, enlargement of the hepatic artery $(>1.5 \mathrm{~mm})$ and the presence of hepatic subcapsular flow are other important findings. Diagnostic accuracy for biliary atresia can be improved to $98 \%$ when the findings are combined [38,41-45]. The diagnosis of biliary atresia can be confirmed with an intraoperative cholangiogram and liver biopsy $[40,41,46]$. Cystic biliary atresia must be differentiated from choledochal cyst, as these two entities have dramatically different management approaches and prognoses. If left untreated, the former progresses to end-stage liver disease and death within the first 3 years of life [39]. The treatment of cystic biliary atresia is urgent surgery with the Kasai procedure [47].

\section{Congenital Simple Hepatic Cysts}

Congenital simple hepatic cysts are rare. These cysts are postulated to arise from in utero aberrant development of the biliary tree 


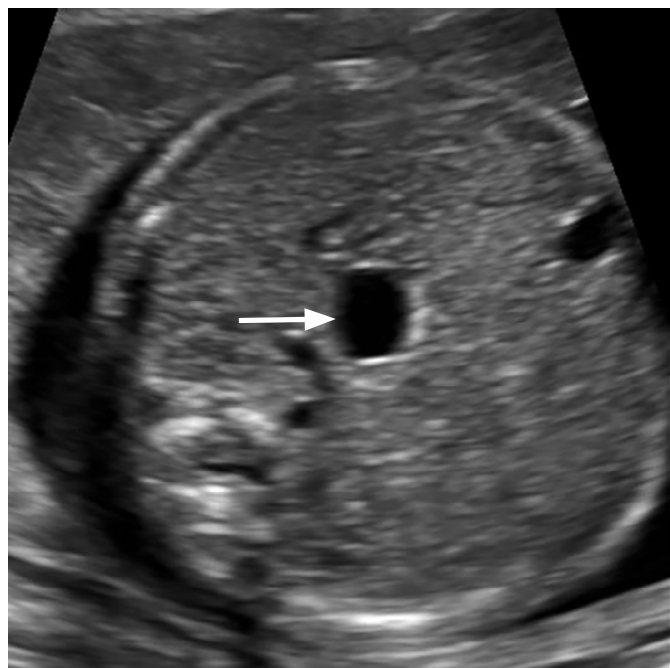

A

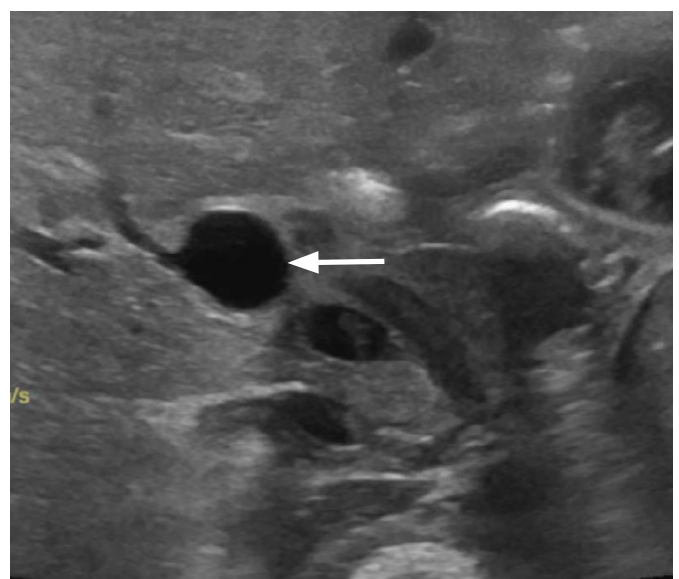

C

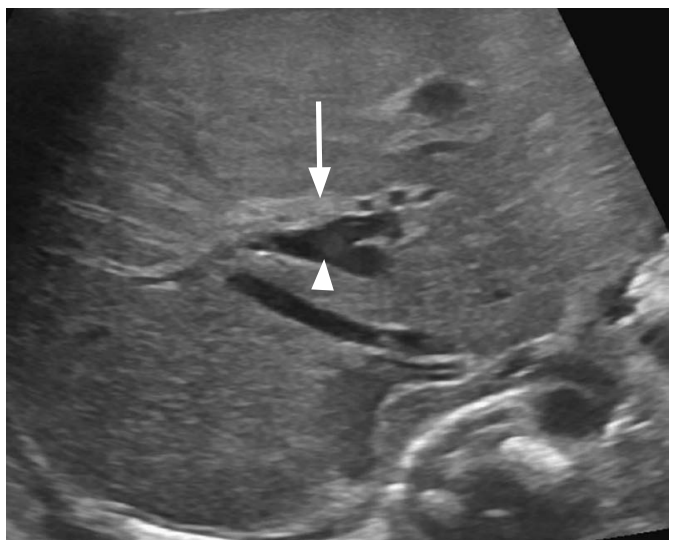

E

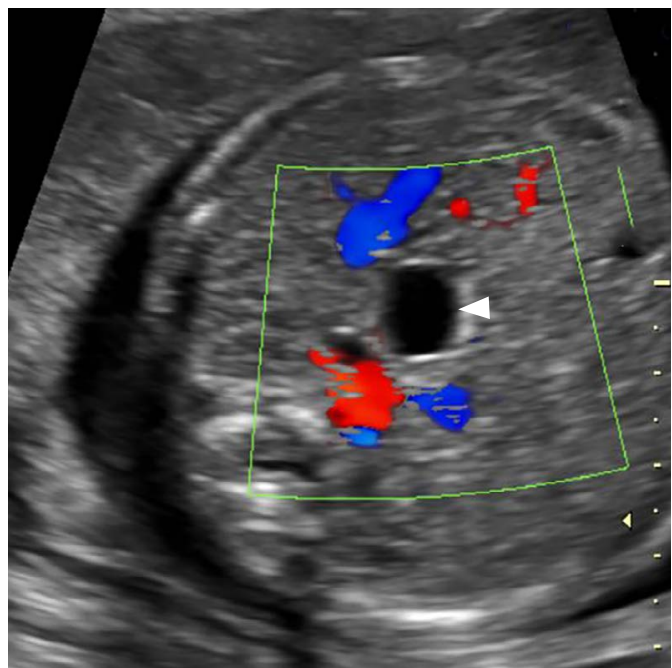

B

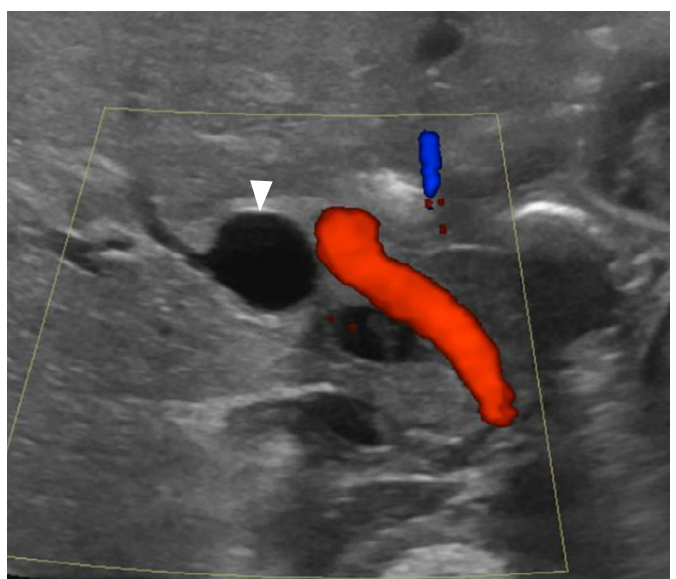

D

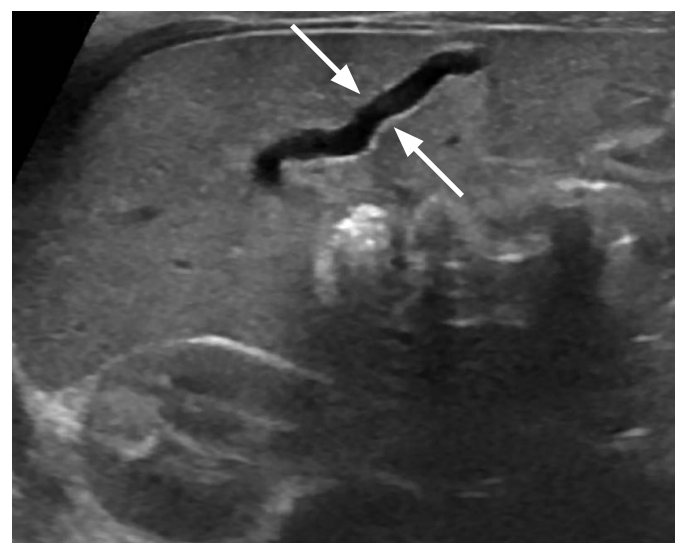

$\mathrm{F}$

Fig. 7. Cystic biliary atresia in a 5-day-old baby girl.

A. A prenatal sonogram at 25 weeks gestational age shows a well-defined anechoic lesion at the porta hepatis (arrow). B. There is absent flow on color Doppler evaluation (arrowhead). C. A postnatal sonogram shows a round well-circumscribed cyst at the porta (arrow). D. There is no vascularity on Doppler imaging (arrowhead). E. A band of echogenic tissue is visualized (arrow) anterior to the right portal vein (arrowhead) representing the triangular cord sign. F. The gallbladder wall is irregular (arrows). 
with obstruction resulting in fluid accumulation, ductule dilatation, and loss of communication with the normal biliary tree. They may also occur after obstruction of the peribiliary glands, either from a congenital malformation or another disease process $[48,49]$. There is no lobar propensity and only a slight female predominance [4850].

On sonography, simple hepatic cysts typically present as solitary, simple, anechoic lesions of variable size within the hepatic parenchyma, usually with a lack of communication with the biliary tree (Fig. 8). Less commonly, they may be large and multilocular. Exophytic simple hepatic cysts may mimic choledochal cysts and cystic biliary atresia; however, hepatic cysts typically present with a normal gallbladder and normal size of the bile ducts and do not connect with the biliary tree. Hepatic cysts are usually not associated with other congenital anomalies [49-52]. They tend to remain stable in size or regress over time. Surgical treatment is reserved for symptomatic or enlarging lesions [48,51-54].

\section{Mesenchymal Hamartoma}

Mesenchymal hamartoma is one of the most common benign liver tumors in children. It results from primitive mesenchymal proliferation, and affects boys slightly more often than girls. Histologically, it is composed of disordered, primitive, fluid-filled mesenchyme, hepatic parenchyma, and bile ducts in addition to stromal cysts of variable size without a capsule. Alpha-fetoprotein

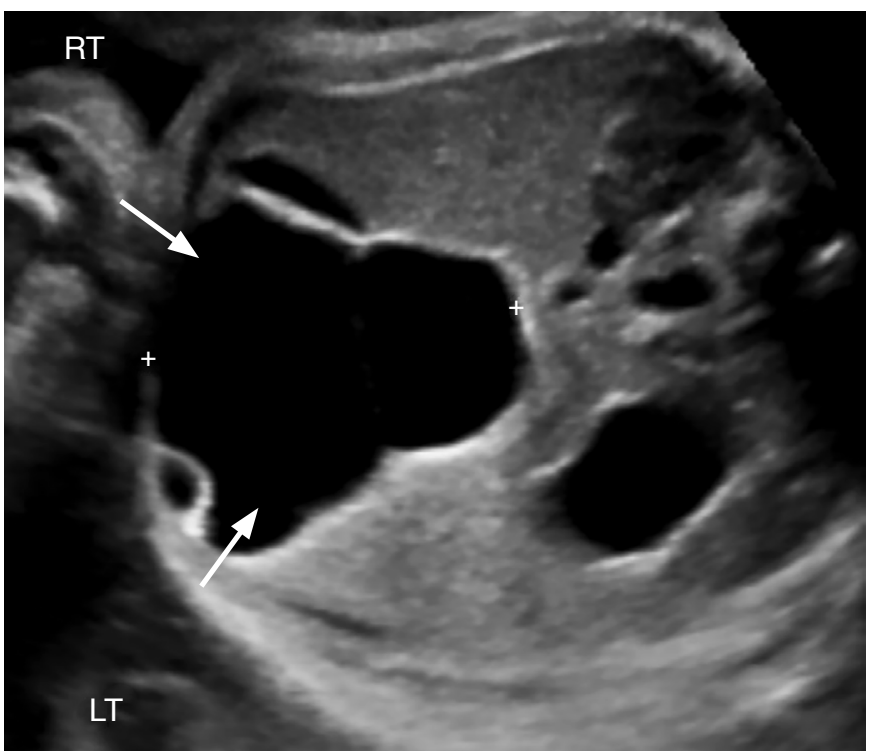

A

Fig. 8. Congenital simple hepatic cyst in a 2-day-old baby girl.

A. A grayscale prenatal sonogram at 35 weeks gestational age shows a lobulated anechoic lesion arising from the right lobe of the liver (arrows). B. A postnatal sonogram shows a thin septum (arrowheads) within the anechoic hepatic lesion (arrow) and no blood flow is present on a Doppler evaluation (not shown). GB, gallbladder; LT, left; RT, right.

e-ultrasonography.org

Ultrasonography 41(1), January 2022

levels are usually normal.

Mesenchymal hamartomas are typically multicystic, heterogeneous masses with septa of variable thickness, most commonly arising in the right lobe of the liver (Fig. 9A-C). They are typically unifocal and show little blood flow on a Doppler exam. When the cysts are tiny, the lesion is hyperechoic and simulates a solid lesion. Calcification and hemorrhage are uncommon. Low-level echoes may be seen within the cyst fluid related to gelatinous contents or hemorrhage. On MRI, mesenchymal hamartomas are complex cystic masses with variable signal intensity, related to the stromal content, amount of protein and presence or absence of hemorrhage within the cyst. The cystic regions are usually hypointense on $\mathrm{T} 1$ and hyperintense on T2-weighted images with enhancement of the septa and solid components (Fig. 9D, E). Mesenchymal hamartomas have an excellent prognosis. The treatment is surgical resection due to rare reports of malignant transformation to undifferentiated embryonal sarcoma [55-59].

\section{Renal and Retroperitoneal Cystic Masses}

\section{Multicystic Dysplastic Kidney}

Multicystic dysplastic kidney (MCDK) is the most common cystic disorder of infants and children. It results from severe obstruction or atresia of the renal pelvis and/or ureter during early urogenital development, leading to disordered parenchymal development. Most

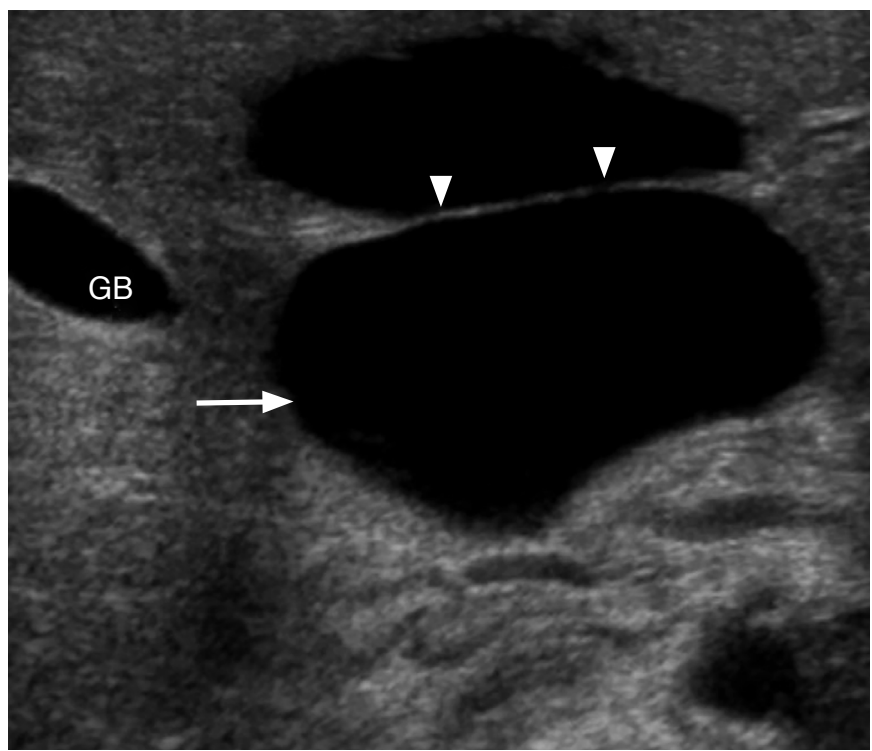

B 


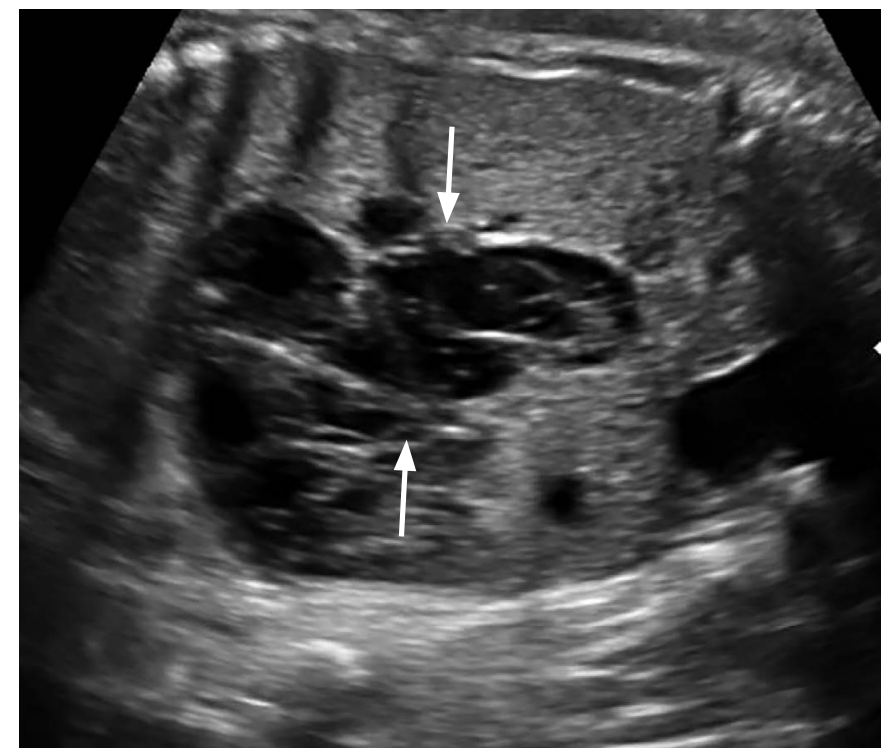

A

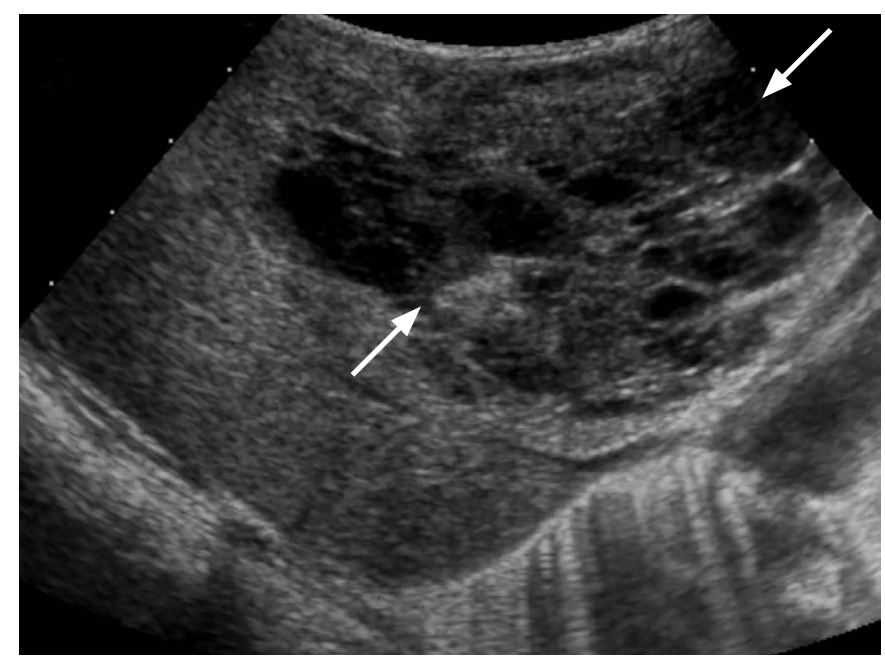

C

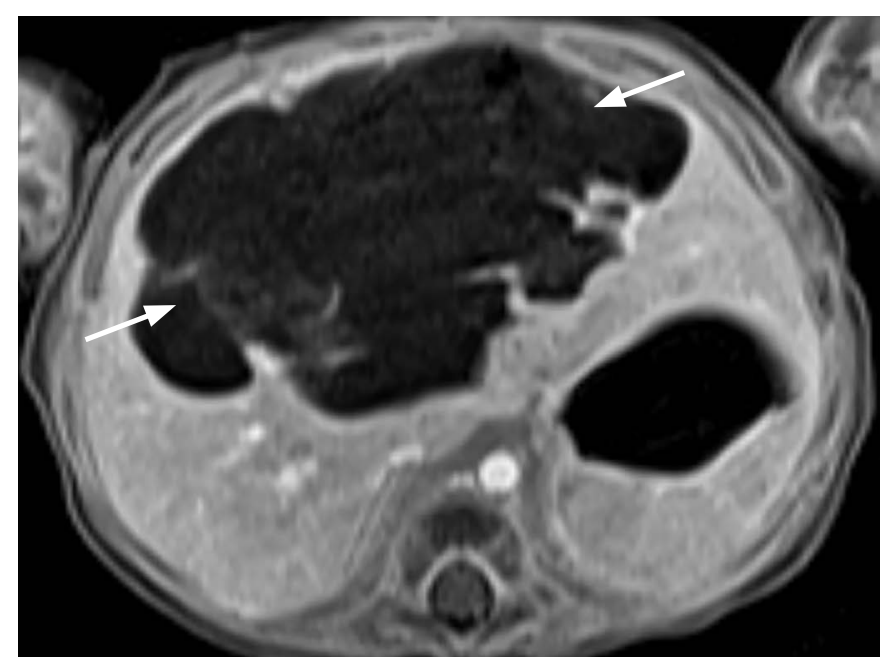

E

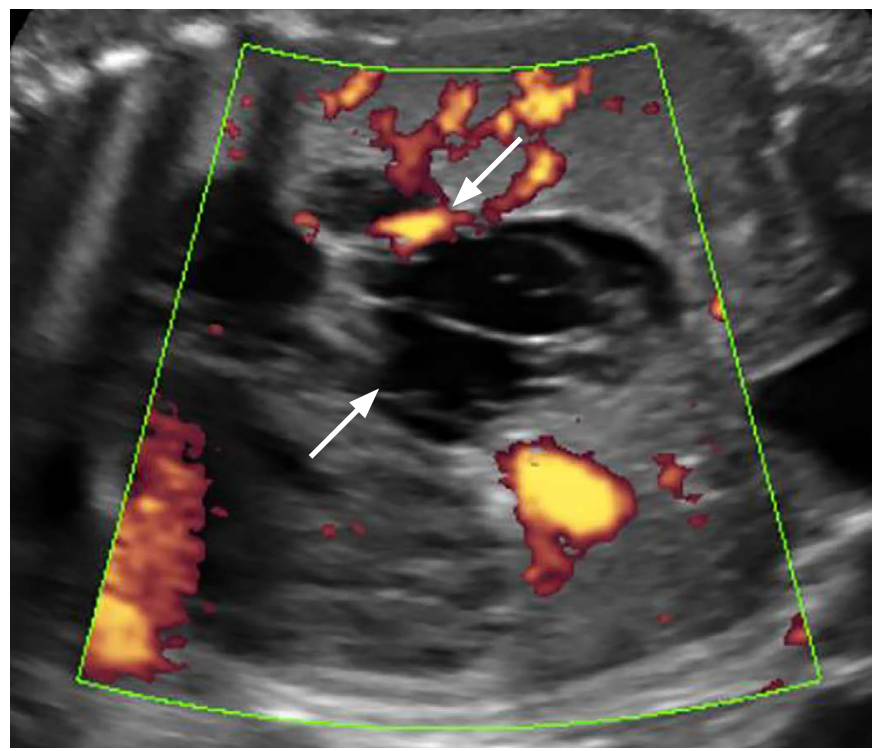

B

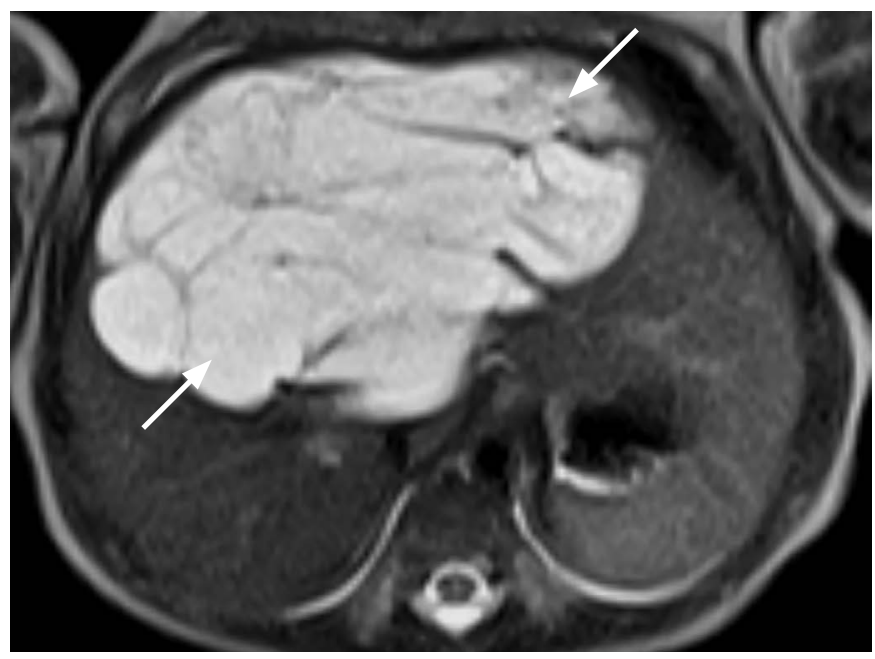

D

Fig. 9. Mesenchymal hamartoma in a 2-day-old baby girl.

A. A prenatal sonogram at 33 weeks gestational age shows a lobulated cystic lesion with echogenic septa of variable size (arrows). $B$. There is mild blood flow in the septa seen on Doppler imaging (arrows). C. A postnatal sonogram reveals a multiseptated cystic hepatic mass (arrows). D. Postnatal magnetic resonance imaging (an axial T2-weighted single-shot turbo spin-echo image) shows a large multiseptated hyperintense cystic hepatic mass (arrows). E. An axial postcontrast T1-weighted spoiled gradient-echo image shows a hypointense cystic mass with mild peripheral and septal enhancement and no solid enhancing component (arrows). 
cases are sporadic, but familial cases have been described $[60,61]$. The two forms of MCDK include the pelvoinfundibular type (common) and the hydronephrotic type (uncommon) [60]. MCDK can occur in half of a duplex kidney, horseshoe kidney, or crossed fused renal ectopia [62]. Vesicoureteral reflux and contralateral ureteropelvic junction (UPJ) obstruction can be associated with this anomaly. Müllerian anomalies may coexist in girls [62].

On imaging, the classic MCDK is characterized by multiple cysts of variable sizes that do not communicate, and poorly defined intervening echogenic renal parenchyma without normal corticomedullary architecture (Fig. 10). The cysts may communicate in the hydronephrotic form mimicking pelvicaliectasis, but with lack of normal renal parenchyma. The affected kidney may be small, normal or enlarged and compensatory hypertrophy of the contralateral kidney is often present. MCDK can be confirmed by renal scintigraphy or magnetic resonance urography (MRU), which document a characteristic absence of renal function [63].

The vast majority of MCDK involute with time and remain asymptomatic [64-66]. The treatment is follow-up; resection is rarely indicated and usually reserved for cases in which there is increasing kidney size rather than involution [60]. Unilateral MCDK with normal contralateral kidney has an excellent prognosis. Renal

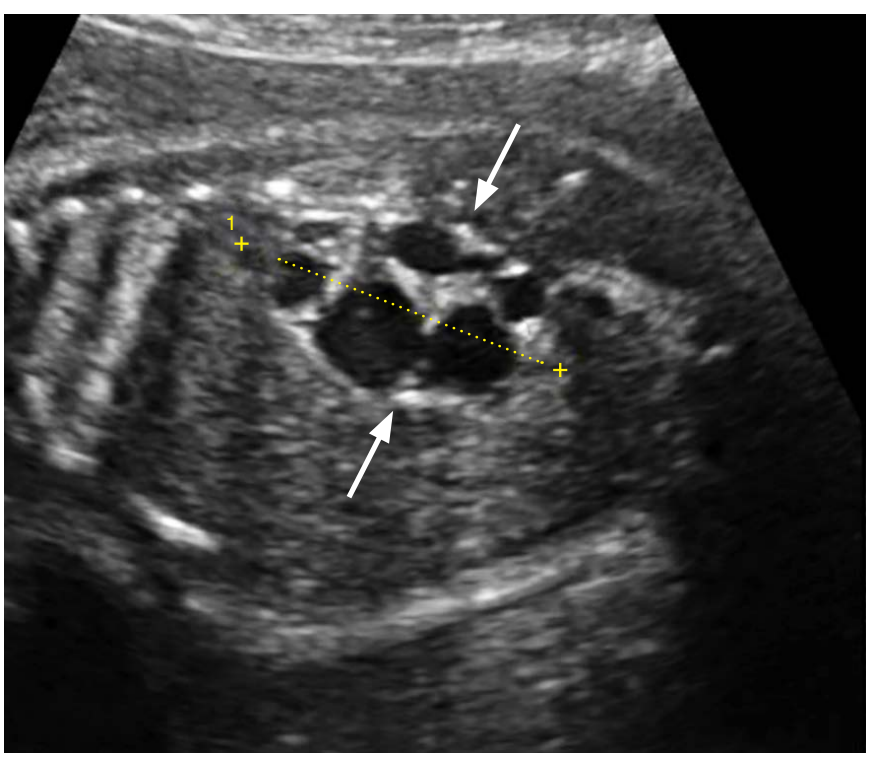

A

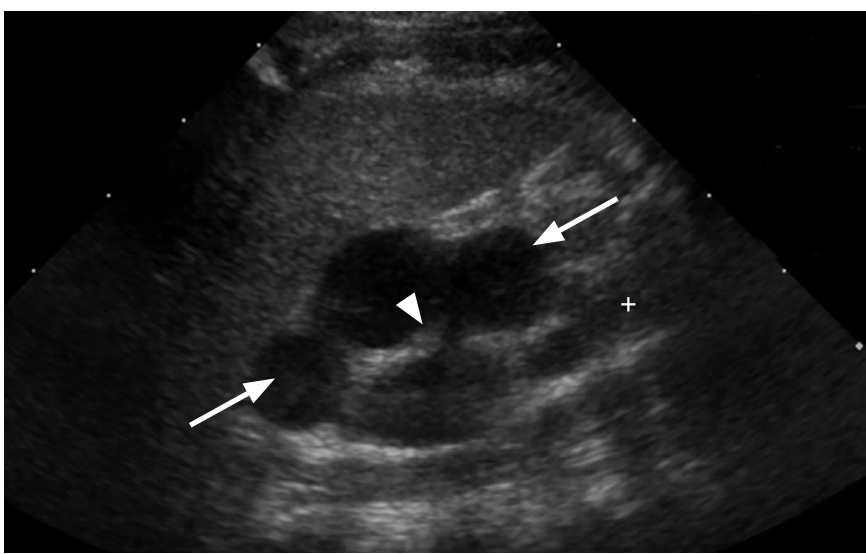

C

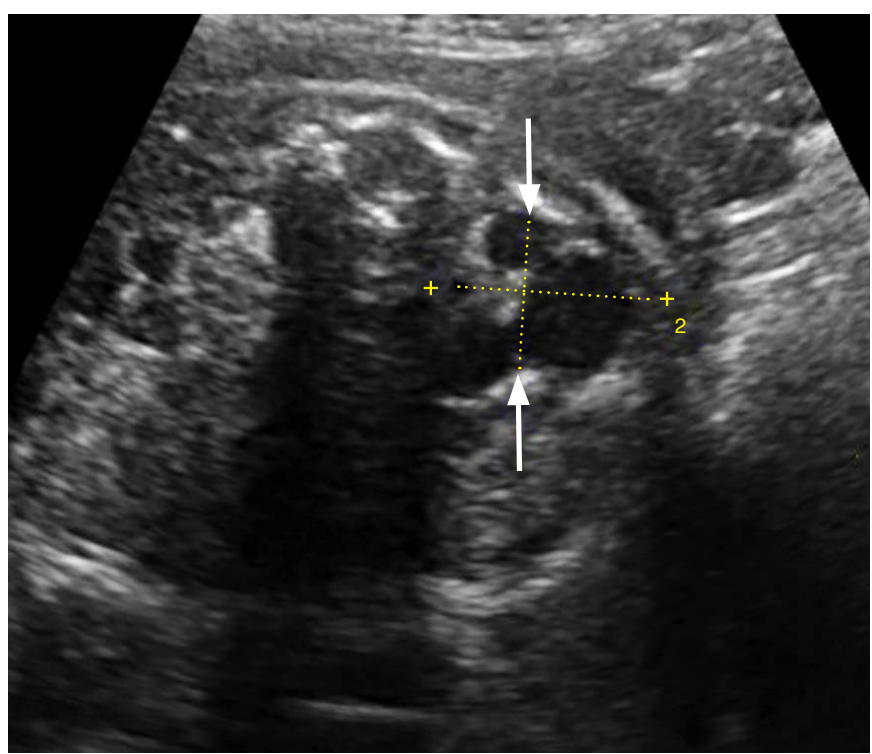

B

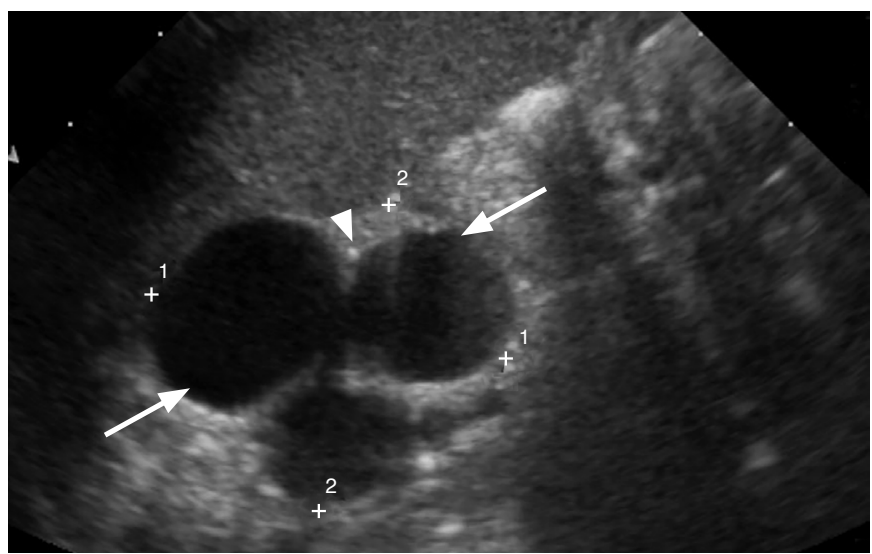

D

Fig. 10. Multicystic dysplastic kidney in a 1-month-old newborn baby girl.

A, B. Longitudinal (A) and transverse (B) prenatal sonograms at 28 weeks gestational age show an enlarged right kidney with multiple noncommunicating cysts of variable size (arrows), and intervening echogenic renal parenchyma with a lack of normal corticomedullary differentiation. C, D. Sagittal (C) and transverse (D) postnatal sonograms reveal a multicystic enlarged right kidney with noncommunicating cysts (arrows) and dysplastic renal parenchyma (arrowheads). 


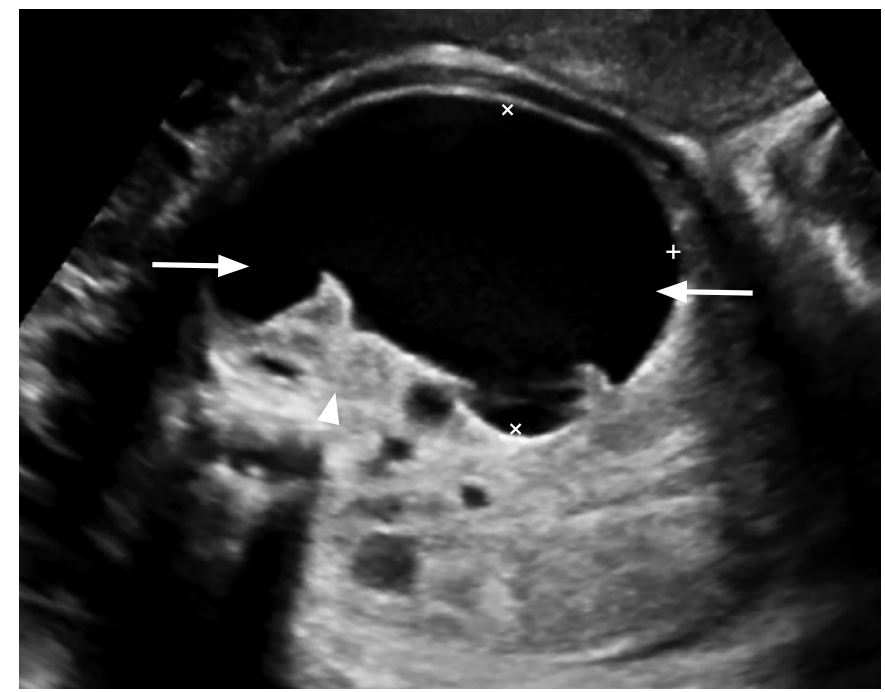

A

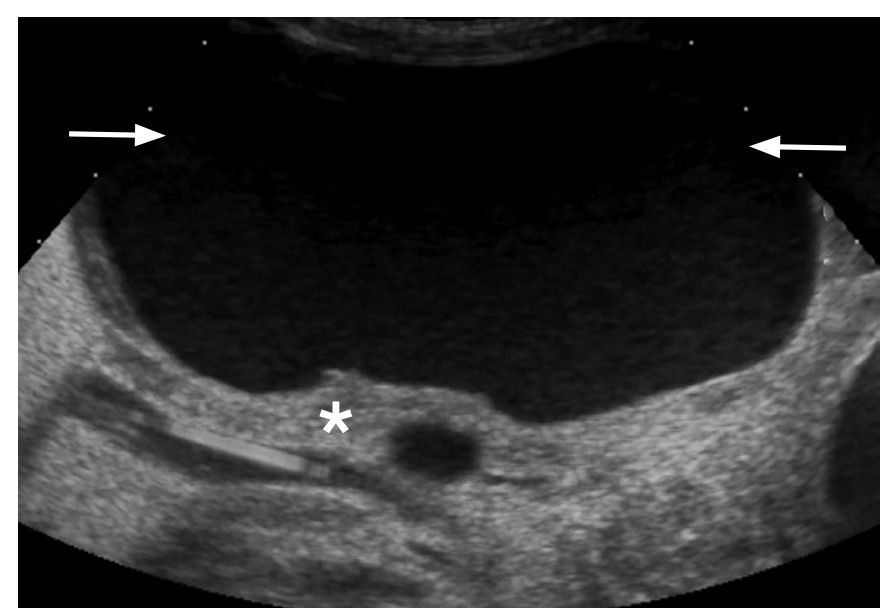

C

insufficiency, pyelonephritis, and scarring can be a problem in cases of unilateral MCDK with an abnormal contralateral kidney. Bilateral involvement is incompatible with life [61].

\section{Urinoma}

Perinatal urinoma is quite rare and presents as an encapsulated collection of urine within the perirenal fascia, caused by calyceal microperforation with leakage of urine resulting from severe renal obstruction. The most common causes of high-grade obstruction are posterior urethral valves or UPJ obstruction [67]. Upper urinary tract obstruction may be associated with a worse prognosis for the kidney than lower urinary tract obstruction [67-69]. Most urinomas are unilateral. The majority occur in boys [70].

On sonography, a urinoma appears as crescentic, round, or elliptical anechoic fluid collection around or abutting an obstructed kidney. It is more often unilocular than septated, seen adjacent to

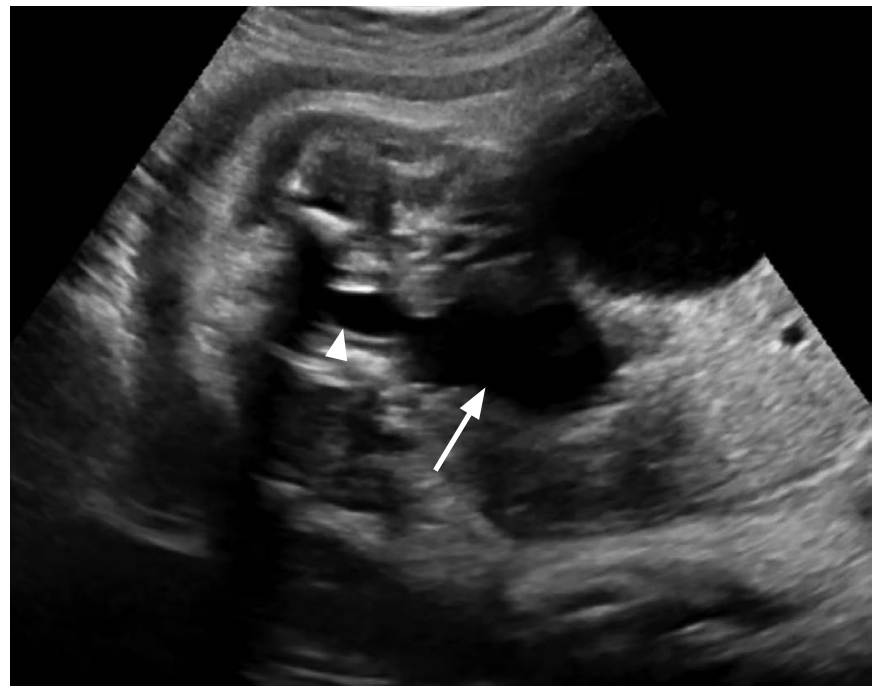

B

Fig. 11. Urinoma in a 1-day-old baby boy.

A. A prenatal sonogram at 36 weeks gestational age shows a wellcircumscribed, large, round, anechoic mass in the left hemiabdomen (arrows), compressing and medially displacing the left kidney (arrowhead). B. A prenatal sonogram inferior to the urinoma shows a distended urinary bladder (arrow) and a dilated posterior urethra (arrowhead), findings consistent with posterior urethral valves. C. A postnatal sonogram reveals a large urinoma on the left side of the abdomen (arrows) causing a severe mass effect and resultant dysplastic changes on the ipsilateral kidney (asterisk).

the spine. The ipsilateral kidney may be distorted and displaced. Associated findings of ipsilateral severe renal obstruction are typically present, characterized by a variable amount of pelvicalyceal and urinary tract dilation and echogenic renal parenchyma (Fig. $11 \mathrm{~A}, \mathrm{C})$. UPJ obstruction or dilated posterior urethra may be present (Fig. 11B) [71]. Nearly all kidneys with urinoma are subsequently shown to have decreased or no function. Spontaneous resolution of urinomas may occur, often reflecting oliguria of the affected kidney, and does not change the prognosis [67]. Management involves treatment of the underlying cause of the urinary tract obstruction [70].

\section{Duplex Kidney with Severe Hydronephrosis Dysplastic Parenchyma of the Upper Moiety}

A duplex kidney consists of upper and lower renal moieties drained by separate collecting systems and/or ureters. It occurs when two 
ureteric buds are present embryologically, or the ureteric bud bifurcates before meeting the metanephric blastema $[72,73]$. Complete duplications with a separate ureter draining each collecting system are less common than incomplete duplications with conjoined draining ureters. The prevalence has been reported to be $0.7 \%-4 \%$, with females affected more than males [73]. The left side is involved more often than the right and bilateral duplication occurs in about $20 \%$ to $40 \%$ of affected individuals. When complete, the upper moiety ureter inserts into the bladder wall inferior and medial to the lower moiety ureter and is more likely to be obstructed. In contrast, the lower moiety ureter is more likely to reflux $[73,74]$. Complete duplication can present with severe hydronephrosis or bladder outlet obstruction due to a large ectopic ureterocele (Fig. 12) [73,74]. Severe hydronephrosis of the upper moiety in a duplex kidney with dysplastic renal parenchyma can mimic a cystic suprarenal mass on sonography.

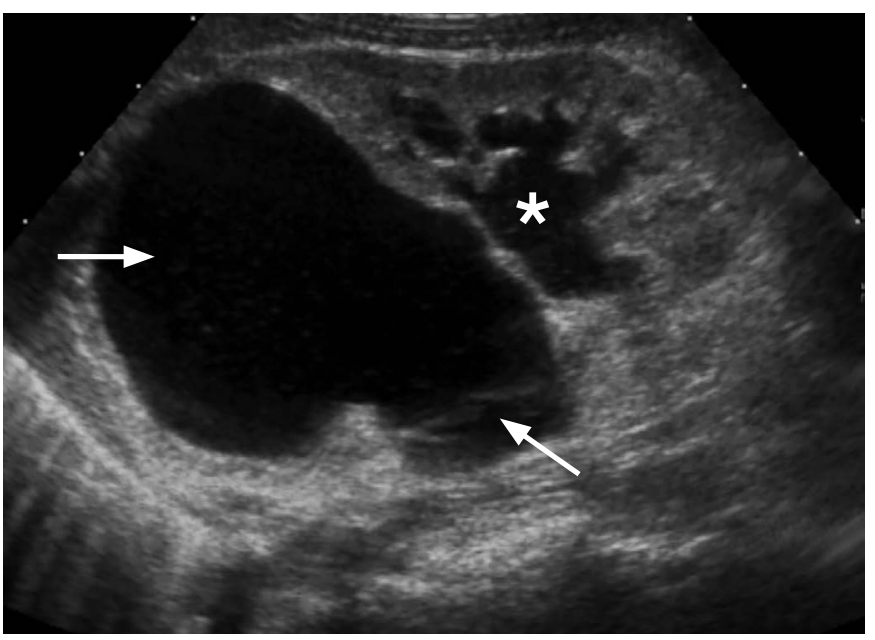

A

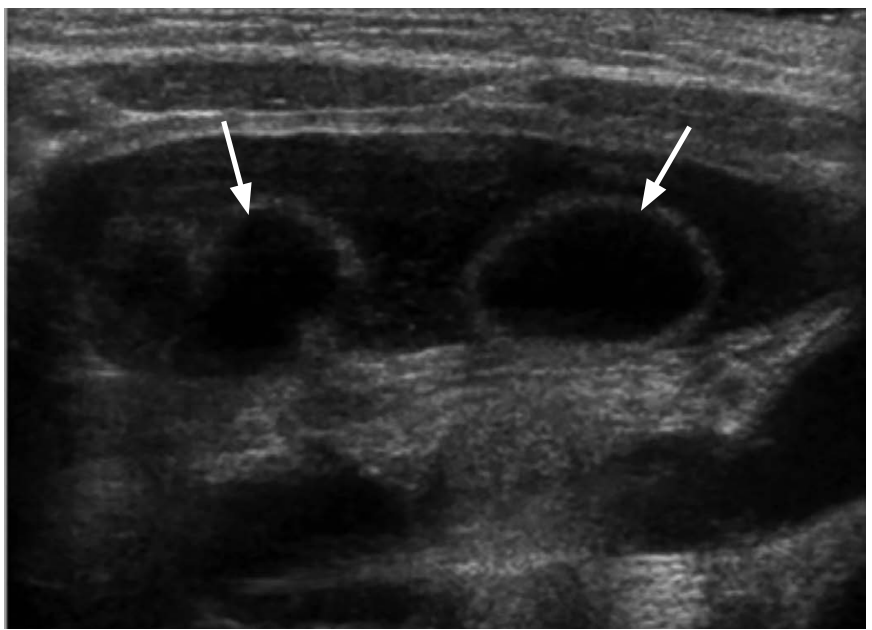

C
The presence of a thin-walled intraluminal cystic lesion within the bladder representing an ectopic ureterocele, confirms that the cystic retroperitoneal mass is related to an obstructed upper renal moiety rather than an adrenal mass (Fig. 12C) [73,75]. Further evaluation of complicated duplex kidneys using voiding cystourethrography (VCUG), and at times MRU may be required [74]. Treatments for upper moiety obstruction include endoscopic puncture or excision of an obstructing ureterocele, ureteroureterostomy, and upper moiety heminephrectomy in the setting of poor or absent kidney function [76].

\section{Cystic Neuroblastoma}

Congenital neuroblastoma is the most common prenatally detected neonatal adrenal neoplasm, and is cystic in $25 \%$ of cases. It is frequently right-sided and may present as localized disease in the newborn or with metastases $[71,77]$. On sonography, cystic

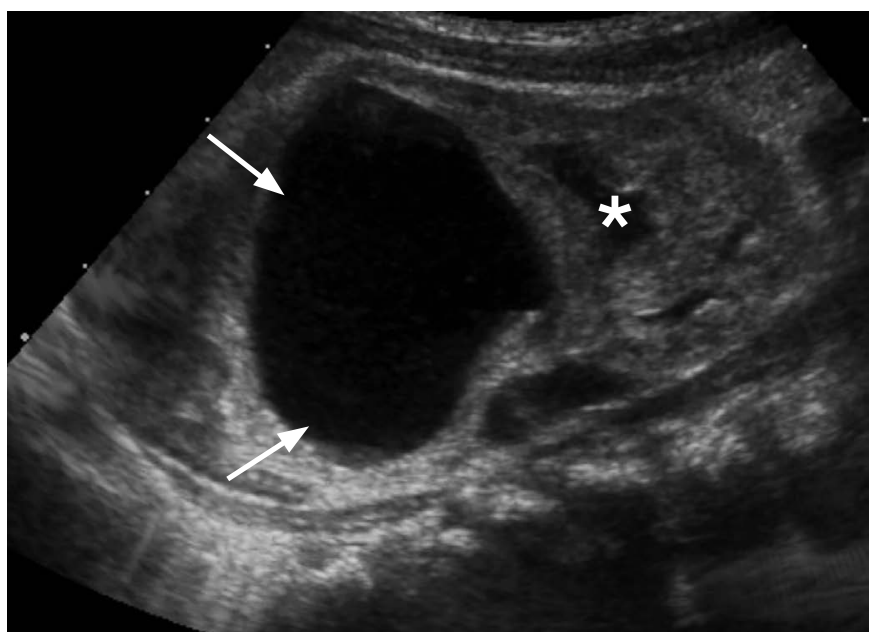

B

Fig. 12. Duplicated upper urinary tract, severe upper-moiety hydronephrosis, and dysplastic renal parenchyma in a 2-day-old baby girl.

A, B. Postnatal longitudinal sonograms of the right (A) and left (B) kidneys show severe upper-moiety pelvicalyceal dilatation (arrows) with marked thinning and increased echogenicity of the overlying renal parenchyma. The lower-moiety collecting systems are also mildly dilated bilaterally (asterisk), likely indicative of coexisting vesicoureteral reflux. C. A transverse sonogram of the urinary bladder reveals bilateral ureteroceles (arrows). 


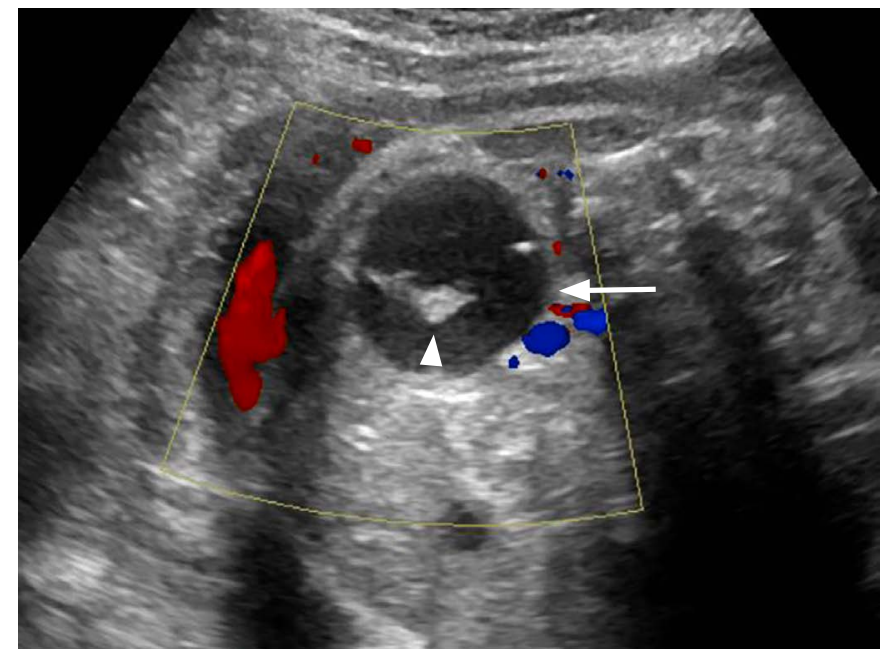

A

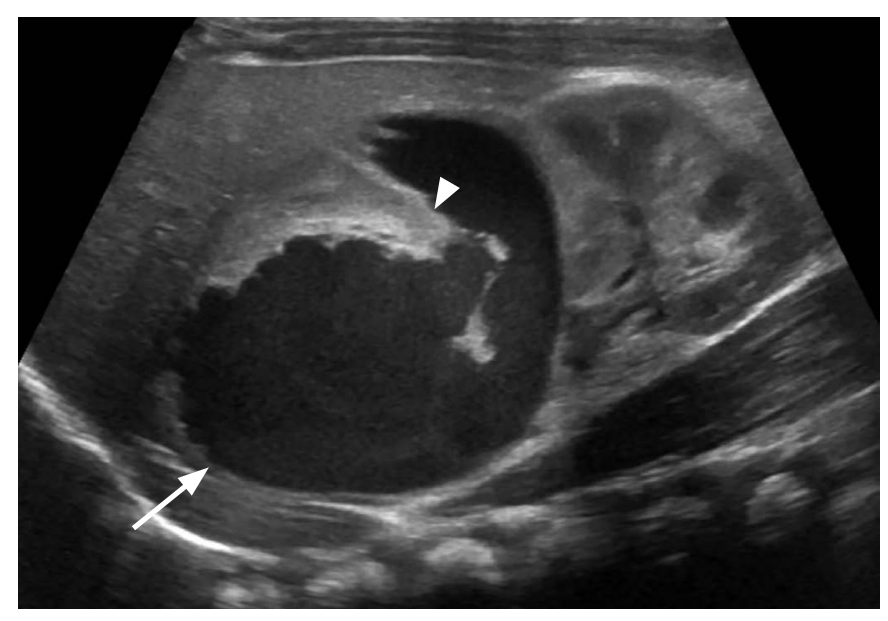

C

Fig. 13. Cystic neuroblastoma in a 1-day-old baby girl.

A, B. Transverse (A) and longitudinal (B) prenatal sonograms at 36 weeks gestational age show a complex cystic mass in the abdomen (arrows) with thick echogenic septa (arrowheads) and absent internal blood flow on color Doppler evaluation. C, D. Longitudinal (C) and transverse (D) postnatal transabdominal sonograms reveal a complex right suprarenal cystic mass (arrows) with thick echogenic septa (arrowheads) mildly compressing the underlying right kidney.

neuroblastoma appears as a complex cystic mass with thick septations and internal blood flow on color Doppler imaging (Fig. 13). Absence of blood flow, however, does not exclude the diagnosis of neuroblastoma. The sonographic findings of cystic neuroblastoma may overlap with those of adrenal hemorrhage; however, the latter uncommonly presents prenatally. In addition, on follow-up ultrasonography, adrenal hemorrhage typically decreases in size and changes echogenicity within the first week and eventually resolves after several weeks, often leaving a residual focus of calcification. In contrast, sonographic appearance changes less rapidly in cystic neuroblastoma and calcification is less common [71]. MRI may be useful for confirming the anatomical origin and for staging and

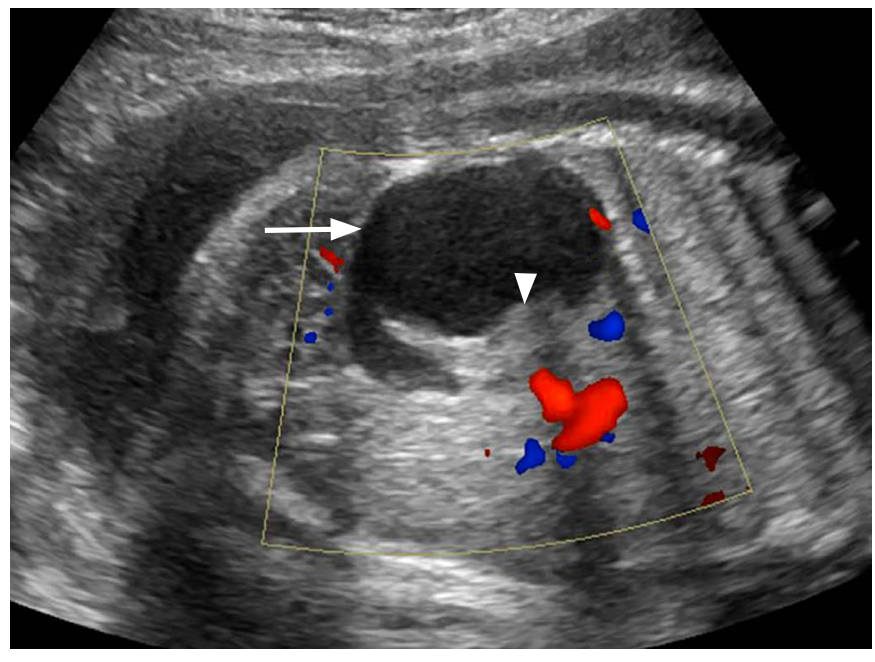

B

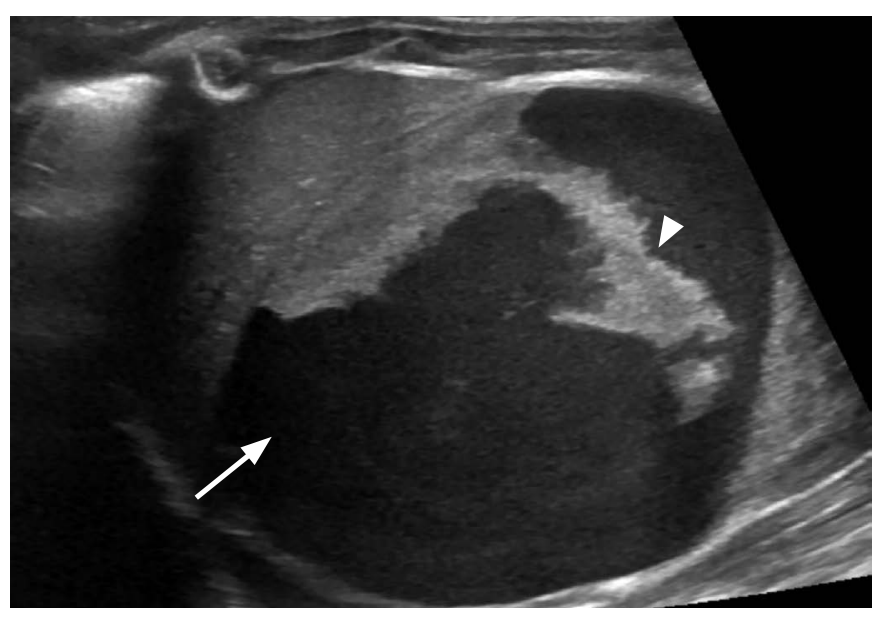

D

evaluating metastases [71]. Most congenital neuroblastomas have a good prognosis; they commonly have a favorable stage $(L 1, L 2$, and MS) and biologic markers. They may resolve spontaneously or remain stable without complications. Surgery may be curative in some cases $[59,78]$.

\section{Pancreatic Cysts}

Congenital pancreatic cysts are rarely encountered; they possess a true epithelium and are thought to arise from a developmental anomaly of the pancreatic ductal system [79]. They may be isolated or associated with systemic diseases such as Beckwith-Wiedemann syndrome, polycystic renal disease, von Hippel-Lindau syndrome, 


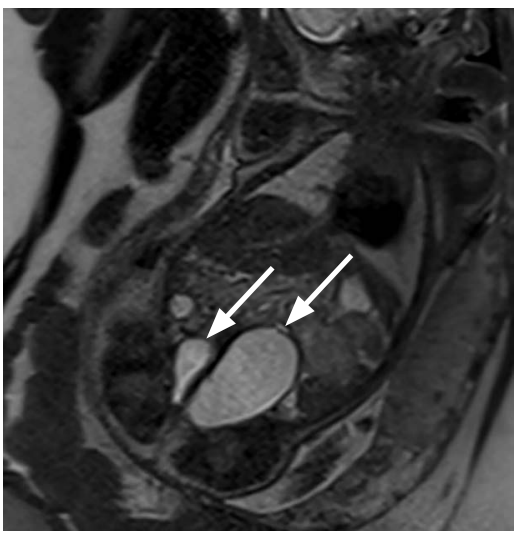

A

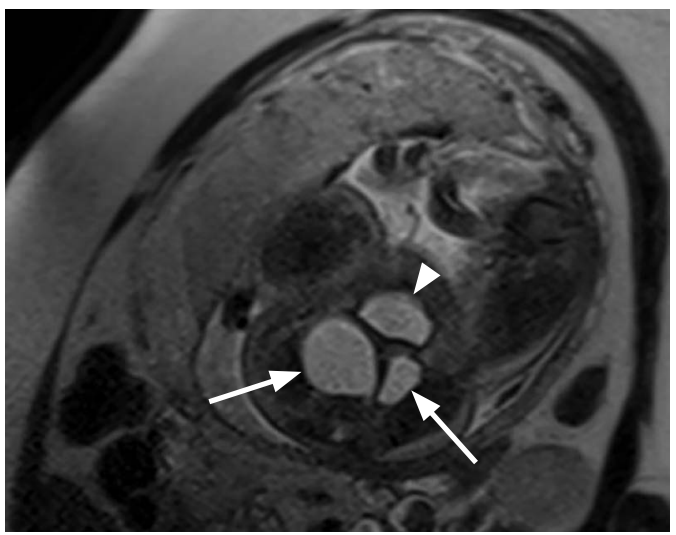

B

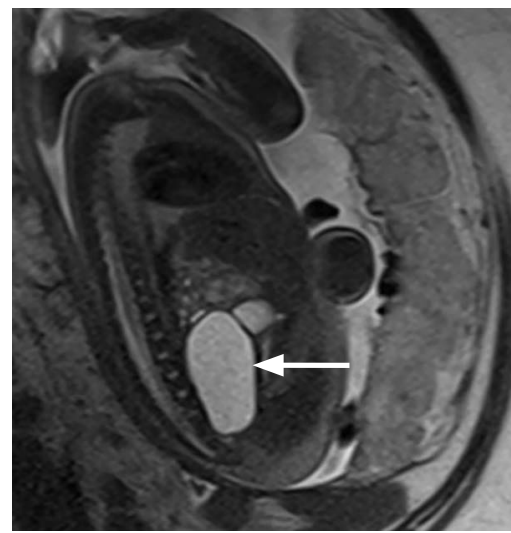

C

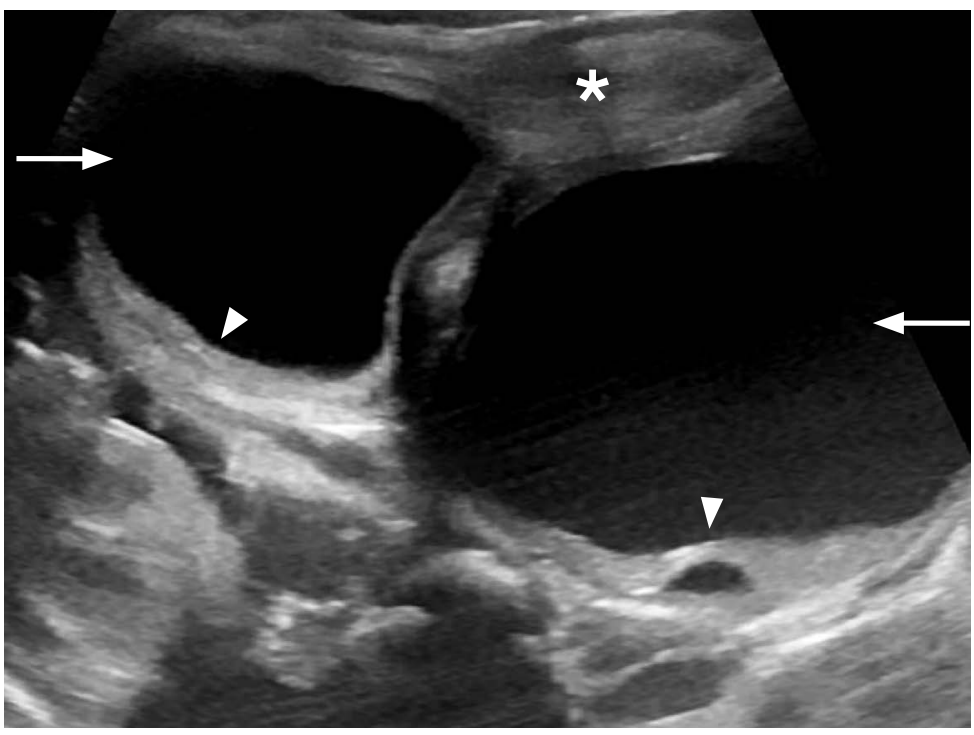

D

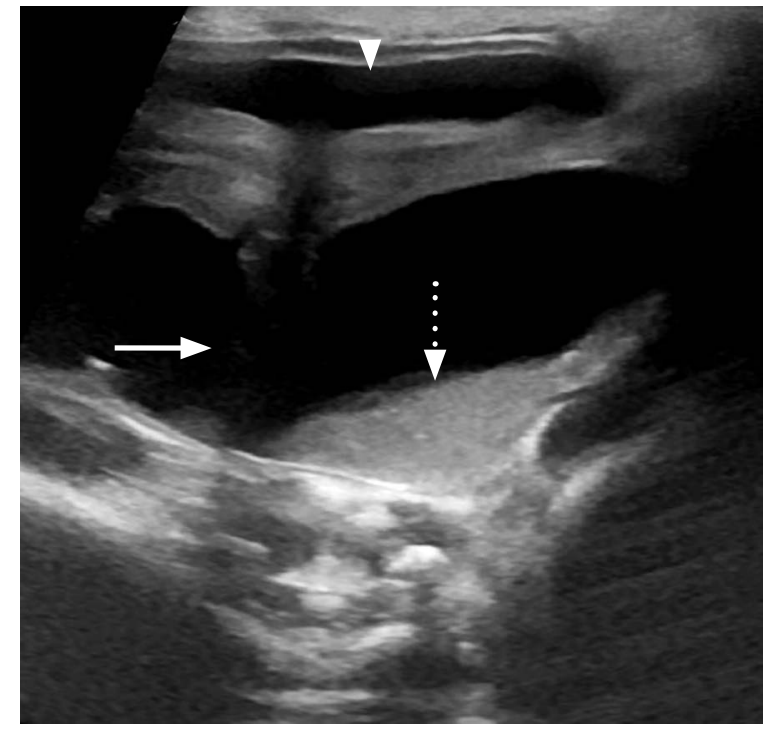

E

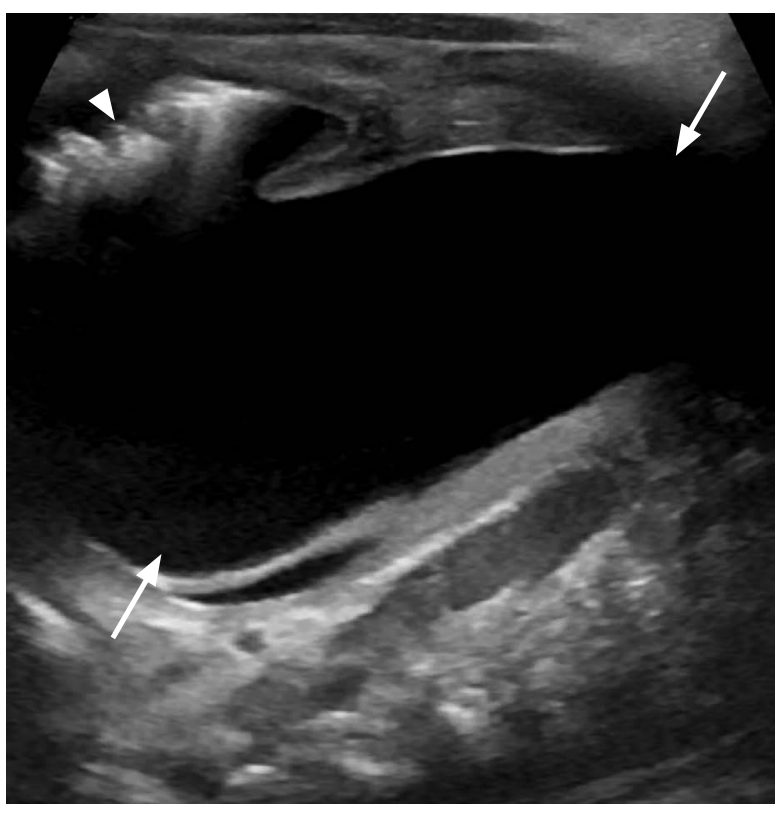

F
Fig. 14. Bilateral hydrocolpos in the setting of vaginal duplication and cloacal malformation in a 1-day-old baby girl.

A. Fetal second-trimester magnetic resonance imaging (a coronal T2weighted single-shot turbo spin-echo image) shows two well-defined dilated tubular lesions in the lower abdomen, funneling to the pelvis, separated by a thin septum (arrows). B. An axial T2-weighted single-shot turbo spin-echo image shows that the bilateral dilated cystic lesions (arrows) are posterior to the bladder (arrowhead). C. A sagittal T2-weighted singleshot turbo spin-echo image shows extension of the right-sided lesion into the abdomen (arrow). D. A postnatal transabdominal transverse sonogram shows two well-defined cystic lesions (arrows) posterior to the bladder (asterisk) with layering echogenic debris (arrowheads). E. A longitudinal sonogram shows a fluid-debris level (dotted arrow) in the cystic lesion (arrow), posterior to the bladder (arrowhead). F. A longitudinal sonogram shows air (arrowhead) in the non-dependent aspect of the cystic lesion (arrows) arising from the congenital fistulous communication with the rectum, a component of the patient's cloacal malformation. 


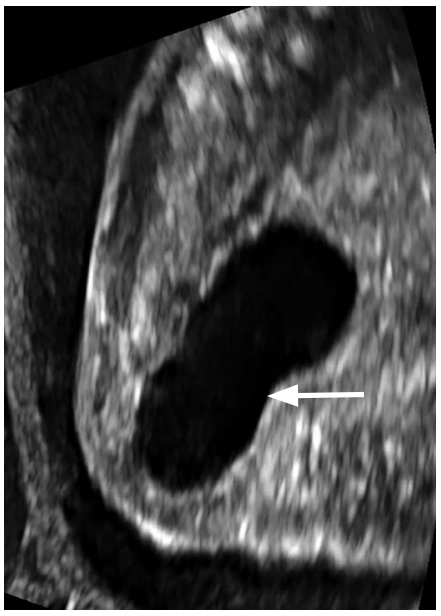

A

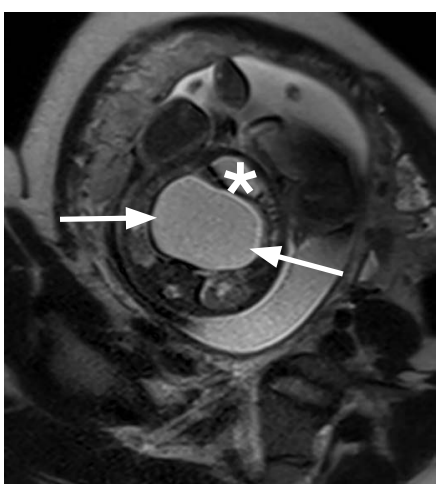

D

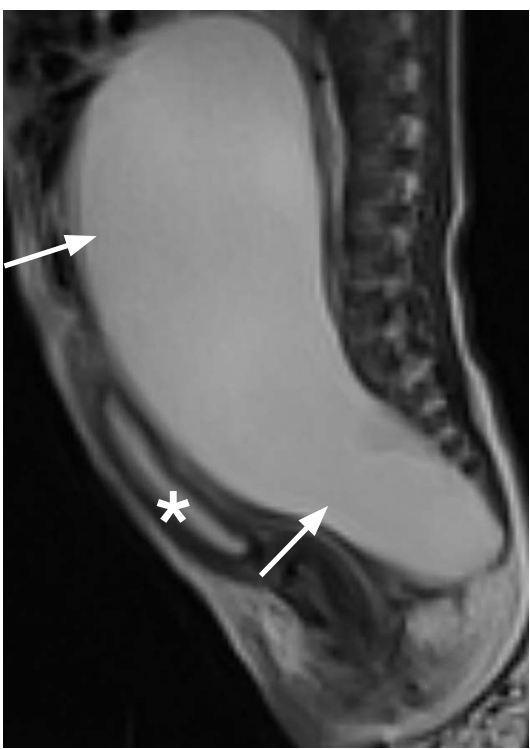

F

B

E
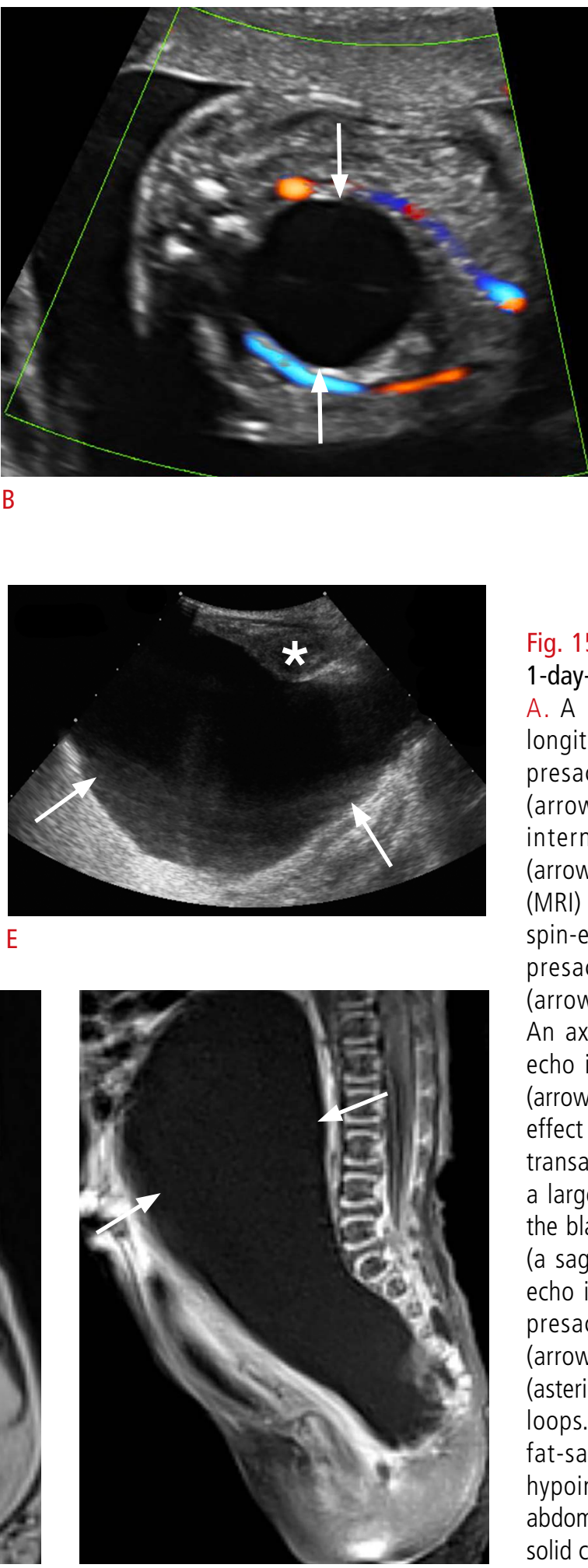

G

Fig. 15. Type IV sacrococcygeal teratoma in a 1-day-old newborn baby girl.

A. A prenatal second-trimester grayscale longitudinal sonogram shows an ovoid cystic presacral mass extending into the abdomen (arrow). B. A transverse sonogram shows no internal blood flow within the cystic mass (arrows). C. Fetal magnetic resonance imaging (MRI) (a sagittal T2-weighted single-shot turbo spin-echo image) shows a hyperintense cystic presacral mass extending into the abdomen (arrow) posterior to the bladder (asterisk). D. An axial T2-weighted single-shot turbo spinecho image shows a hyperintense cystic mass (arrows) posterior to the bladder, exerting a mass effect on the bladder (asterisk). E. A postnatal transabdominal longitudinal sonogram reveals a large pelvic cystic mass (arrows) compressing the bladder anteriorly (asterisk). F. Postnatal MRI (a sagittal T2-weighted single-shot turbo spinecho image) shows a large hyperintense cystic presacral mass, extending into the abdomen (arrows), causing a mass effect on the bladder (asterisk), and displacing the surrounding bowel loops. G. A sagittal postcontrast T1-weighted fat-saturated image shows a non-enhancing hypointense ovoid cystic presacral mass, with abdominal extension (arrows) and no enhancing solid component. 
asphyxiating thoracic dystrophy, and heterotaxy syndrome [7983]. They are small and anechoic on sonography, unilocular or multilocular, and mostly located in the pancreatic body or tail. They are surrounded by normal parenchyma and rarely communicate with the ductal system. Complications include cyst infection, inflammation, or rupture; cholangitis; pancreatitis; and peritonitis $[18,80]$. Surgical removal is only necessary for symptomatic cysts or those concerning for neoplasia [79-81].

\section{Splenic Cysts}

Congenital splenic cysts are rare. They are true cysts with an epithelial lining [84]. The pathogenesis is unclear, although these cysts have been proposed to arise from production of fluid from pluripotent cells or from the normal lymph spaces in the spleen [85]. Congenital splenic cysts are typically isolated and asymptomatic, and they rarely develop complications $[84,86]$. They are small, anechoic on sonography, with a smooth imperceptible wall, no mural calcification, and no color Doppler flow. The surrounding parenchyma is usually normal [85]. Most congenital splenic cysts remain stable, decrease in size, or completely regress [85-87]. Although rare, sporadic cases of rupture, hemorrhage, and infection have been reported in the literature $[88,89]$. Symptomatic and large congenital splenic cysts may require percutaneous drainage and/or sclerotherapy. Total or partial splenectomy and partial cystectomy with marsupialization or cyst fenestration have been described [84].

\section{Cystic Masses Arising from the Pelvis}

\section{Hydrocolpos and Hydrometrocolpos}

Congenital hydrocolpos is uncommon, characterized by fluid distention of the vagina, secondary to vaginal tract obstruction. Hydrometrocolpos refers to fluid accumulation in the obstructed vagina and uterus. It is believed to result from increased mucus secretion by the vagina and cervix in response to maternal hormones; the mucus gradually accumulates, expands, and builds up into a pelvic mass due to vaginal obstruction. Persistent urogenital sinus and cloacal dysgenesis are commonly associated with congenital hydrocolpos; mixing of urine, vaginal secretions, and meconium will be seen in this context. Vaginal tract obstruction can also occur from vaginal atresia, transverse vaginal septum, and imperforate hymen. Most cases of congenital hydrocolpos are sporadic, but this condition can be associated with several syndromes $[90,91]$.

On sonography, hydrocolpos appears as a unilocular, fluid-filled pelvic mass posterior to the bladder with characteristic funneling to the perineum. The cervix may be opened with contiguous fluid distending the uterine cavity, usually of lesser magnitude than the vagina because of the thick muscular uterine wall. Fluid-fluid level or mobile echoes may be seen within the cystic mass (Fig. 14). Further imaging with a genitogram, VCUG, and MRI is usually required in patients with coexisting genitourinary anomalies [90-93].

The most common complication of congenital hydrocolpos is hydronephrosis and renal failure. Intestinal obstruction, cardiorespiratory distress, and sepsis can also occur $[90,91,94]$. The initial management is often urgent percutaneous drainage, followed by surgical management, aimed at correcting the obstruction [9092].

\section{Cystic Sacrococcygeal Teratoma}

Sacrococcygeal teratoma is the most common congenital neoplasm of neonates, with a female preponderance of $4: 1[59,95]$. The tumors may be purely cystic in $15 \%$ of cases. Teratomas are composed of all three germ cell layers (ectoderm, mesoderm, and endoderm). They commonly occur along the midline of the body, anywhere from the coccyx to the pineal gland. The majority of teratomas arise from the sacrococcygeal region, and less frequently in the retroperitoneum [95-97]. Sacrococcygeal teratomas are classified according to the American Academy of Pediatrics Surgery Section Survey into four types (I-IV) based on the amount of mass present externally versus internally, which has important prognostic implications. Cystic teratomas are anechoic on sonography without internal blood flow. In type I, the cystic mass is predominantly external; in type II, there is extension to the presacral space; in type III, the mass extends into the abdominal cavity; and in type IV, the mass is entirely internal $[59,98-100]$. Further MRI is useful to assess the size, characteristics, and extent of the mass to optimize management (Fig. 15) $[95,97]$. Associated conditions may include hydronephrosis, renal dysplasia, urethral atresia, urinary ascites, hydrocolpos, and undescended testes $[59,96,99,100]$. Predominantly cystic tumors have a better prognosis, presumably because of the lower prevalence of vascular steal and hemorrhage. The treatment for sacrococcygeal teratoma is complete resection $[95,97,100]$.

\section{Conclusion}

Prenatally detected abdominal and pelvic cystic lesions can arise from many structures in the abdomen and have a broad differential diagnosis. Ultrasonography should be the first imaging investigation following birth and is often the only imaging study required to arrive at a diagnosis, supplemented by MRI when necessary. An organized anatomical approach and attention to characteristic sonographic findings aid diagnosis and guide appropriate management. 
ORCID: Bernadette Wambui Muthee: https://orcid.org/0000-0001-7207-922X; Heather J. Bray: https://orcid.org/0000-0003-3019-0661

\section{Author Contributions}

Conceptualization: Bray HJ. Data acquisition: Muthee BW, Bray HJ. Data analysis or interpretation: Muthee BW, Bray HJ. Drafting of the manuscript: Muthee BW. Critical revision of the manuscript: Muthee BW, Bray HJ. Approval of the final version of the manuscript: all authors.

\section{Conflict of Interest}

No potential conflict of interest relevant to this article was reported.

\section{Acknowledgments}

The authors thank Jim Potts, PhD for assistance with manuscript preparation and institutional research ethics board approval.

\section{References}

1. Gupta P, Sharma R, Kumar S, Gadodia A, Roy KK, Malhotra N, et al. Role of MRI in fetal abdominal cystic masses detected on prenatal sonography. Arch Gynecol Obstet 2010;281:519-526.

2. Marrone L, Liberati $M$, Khalil A, Rizzo G, Leombroni M, Buca D, et al. Outcome of fetal gastro-intestinal cysts: a systematic review and meta-analysis. Prenat Diagn 2016;36:966-972.

3. Sherwood W, Boyd P, Lakhoo K. Postnatal outcome of antenatally diagnosed intra-abdominal cysts. Pediatr Surg Int 2008;24:763765.

4. Catania VD, Briganti V, Di Giacomo V, Miele V, Signore F, de Waure C, et al. Fetal intra-abdominal cysts: accuracy and predictive value of prenatal ultrasound. J Matern Fetal Neonatal Med 2016;29:16911699.

5. Trinh TW, Kennedy AM. Fetal ovarian cysts: review of imaging spectrum, differential diagnosis, management, and outcome. Radiographics 2015;35:621-635.

6. Ziereisen F, Guissard G, Damry N, Avni EF. Sonographic imaging of the paediatric female pelvis. Eur Radiol 2005;15:1296-1309.

7. Schmahmann S, Haller JO. Neonatal ovarian cysts: pathogenesis, diagnosis and management. Pediatr Radiol 1997;27:101-105.

8. Ozcan HN, Balci S, Ekinci S, Gunes A, Oguz B, Ciftci AO, et al. Imaging findings of fetal-neonatal ovarian cysts complicated with ovarian torsion and autoamputation. AJR Am J Roentgenol 2015;205:185-189.

9. Jeanty C, Frayer EA, Page R, Langenburg S. Neonatal ovarian torsion complicated by intestinal obstruction and perforation, and review of the literature. J Pediatr Surg 2010;45:e5-e9.

10. Llorens Salvador R, Sanguesa Nebot C, Pacheco Usmayo A, Pico Aliaga S, Garces Inigo E. Neonatal ovarian cysts: ultrasound assessment and differential diagnosis. Radiologia 2017;59:31-39.

11. Archontaki S, Vial Y, Hanquinet S, Meuli R, Alamo L. Magnetic resonance imaging of fetal pelvic cysts. Abdom Radiol (NY) 2016;41:2445-2454.

12. Turgal M, Ozyuncu O, Yazicioglu A. Outcome of sonographically suspected fetal ovarian cysts. J Matern Fetal Neonatal Med 2013;26:1728-1732.

13. Papic JC, Billmire DF, Rescorla FJ, Finnell SM, Leys CM. Management of neonatal ovarian cysts and its effect on ovarian preservation. J Pediatr Surg 2014;49:990-993.

14. Cesca E, Midrio P, Boscolo-Berto R, Snijders D, Salvador L, D'Antona $D$, et al. Conservative treatment for complex neonatal ovarian cysts: a long-term follow-up analysis. J Pediatr Surg 2013;48:510-515.

15. Narlawar RS, Rao JR, Karmarkar SJ, Gupta A, Hira P. Sonographic findings in a duodenal duplication cyst. J Clin Ultrasound 2002;30:566-568.

16. Ben-Ishay O, Connolly SA, Buchmiller TL. Multiple duplication cysts diagnosed prenatally: case report and review of the literature. Pediatr Surg Int 2013;29:397-400.

17. Cheng G, Soboleski D, Daneman A, Poenaru D, Hurlbut D. Sonographic pitfalls in the diagnosis of enteric duplication cysts. AJR Am J Roentgenol 2005;184:521-525.

18. Silva CT, Engel C, Cross SN, Copel JE, Morotti RA, Baker KE, et al. Postnatal sonographic spectrum of prenatally detected abdominal and pelvic cysts. AJR Am J Roentgenol 2014;203:W684-W696.

19. Larson SD, Hebra A. Meconium pseudocyst in a newborn. J Am Coll Surg 2006;203:399.

20. Carroll BA, Moskowitz PS. Sonographic diagnosis of neonatal meconium cyst. AJR Am J Roentgenol 1981;137:1262-1264.

21. Yang WT, Ho SS, Metreweli C. Case report: antenatal sonographic diagnosis of meconium peritonitis and subsequent evolving meconium pseudocyst formation without peritoneal calcification. Clin Radiol 1997;52:477-479.

22. Douglas D. Meconium pseudocyst. Pediatr Radiol 2010;40 Suppl 1:S105.

23. Khan SA, Khare M, Dagash H, Kairamkonda V. Meconium pseudocyst presenting as massive ascites in a new-born. Radiol Case Rep 2019;14:235-237.

24. Minato M, Okada T, Miyagi H, Honda S, Takazawa K, Kubota KC, et al. Meconium pseudocyst with particular pathologic findings: a case report and review of the literature. J Pediatr Surg 2012;47:e9e12.

25. Oliver ER, Coleman BG, DeBari SE, Victoria T, Looney DM, Horii SC, et al. Fetal lymphatic malformations: more variable than we think? J Ultrasound Med 2017;36:1051-1058.

26. Elluru RG, Balakrishnan K, Padua HM. Lymphatic malformations: diagnosis and management. Semin Pediatr Surg 2014;23:178-185.

27. Francavilla $M L$, White $C L$, Oliveri $B$, Lee $E Y$, Restrepo $R$. Intraabdominal lymphatic malformations: pearls and pitfalls of 
diagnosis and differential diagnoses in pediatric patients. AJR Am J Roentgenol 2017;208:637-649.

28. Bagrodia N, Defnet AM, Kandel JJ. Management of lymphatic malformations in children. Curr Opin Pediatr 2015;27:356-363.

29. Kosir MA, Sonnino RE, Gauderer MW. Pediatric abdominal lymphangiomas: a plea for early recognition. J Pediatr Surg 1991;26:1309-1313.

30. Stoupis C, Ros PR, Abbitt PL, Burton SS, Gauger J. Bubbles in the belly: imaging of cystic mesenteric or omental masses. Radiographics 1994;14:729-737.

31. Parada Villavicencio C, Adam SZ, Nikolaidis P, Yaghmai V, Miller FH. Imaging of the urachus: anomalies, complications, and mimics. Radiographics 2016;36:2049-2063.

32. Yu JS, Kim KW, Lee HJ, Lee YJ, Yoon CS, Kim MJ. Urachal remnant diseases: spectrum of CT and US findings. Radiographics 2001;21:451-461.

33. van Rijn RR, Nievelstein RA. Paediatric ultrasonography of the liver, hepatobiliary tract and pancreas. Eur J Radiol 2014;83:1570-1581.

34. Nievelstein RA, Robben SG, Blickman JG. Hepatobiliary and pancreatic imaging in children-techniques and an overview of nonneoplastic disease entities. Pediatr Radiol 2011;41:55-75.

35. Todani T, Watanabe Y, Narusue M, Tabuchi K, Okajima K. Congenital bile duct cysts: classification, operative procedures, and review of thirty-seven cases including cancer arising from choledochal cyst. Am J Surg 1977;134:263-269.

36. Wax BN, Durie NM, Khullar P, Price AP, Coren CV, Katz DS. Radiology-Pathology Conference: choledochal cyst. Clin Imaging 2007;31:269-272.

37. Rozel C, Garel L, Rypens F, Viremouneix L, Lapierre C, Decarie $\mathrm{JC}$, et al. Imaging of biliary disorders in children. Pediatr Radiol 2011;41:208-220.

38. Zhou LY, Guan BY, Li L, Xu ZF, Dai CP, Wang W, et al. Objective differential characteristics of cystic biliary atresia and choledochal cysts in neonates and young infants: sonographic findings. J Ultrasound Med 2012;31:833-841.

39. Schooler GR, Mavis A. Cystic biliary atresia: a distinct clinical entity that may mimic choledochal cyst. Radiol Case Rep 2018;13:415418.

40. Lakshminarayanan B, Davenport M. Biliary atresia: a comprehensive review. J Autoimmun 2016;73:1-9.

41. Mahalik SK, Mitra S, Patra S, Das K. Cystic biliary atresia or atretic choledochal cyst: a continuum in infantile obstructive cholangiopathy. Fetal Pediatr Pathol 2019;38:477-483.

42. Tanaka N, Ueno T, Takama Y, Fukuzawa M. Diagnosis and management of biliary cystic malformations in neonates. J Pediatr Surg 2010;45:2119-2123.

43. Morel B, Kolanska K, Dhombres F, Jouannic JM, Franchi-Abella S, Ducou Le Pointe $\mathrm{H}$, et al. Prenatal ultrasound diagnosis of cystic biliary atresia. Clin Case Rep 2015;3:1050-1051.
44. Shen O, Sela HY, Nagar H, Rabinowitz R, Jacobovich E, Chen D, et al. Prenatal diagnosis of biliary atresia: a case series. Early Hum Dev 2017;111:16-19.

45. Zhou L, Shan Q, Tian W, Wang Z, Liang J, Xie X. Ultrasound for the diagnosis of biliary atresia: a meta-analysis. AJR Am J Roentgenol 2016;206:W73-W82.

46. Tanaka H, Sasaki H, Wada M, Sato T, Kazama T, Nishi K, et al. Postnatal management of prenatally diagnosed biliary cystic malformation. J Pediatr Surg 2015;50:507-510.

47. Hartley JL, Davenport M, Kelly DA. Biliary atresia. Lancet 2009;374:1704-1713.

48. Nordin AB, Fallon SC, Carter BA, Brandt ML. Congenital hepatic cyst with antenatal diagnosis: a case report and literature review. Pediatr Surg Int 2013;29:847-850.

49. Macken MB, Wright JR Jr, Lau H, Cooper MC, Grantmyre EB, Thompson DL, et al. Prenatal sonographic detection of congenital hepatic cyst in third trimester after normal second-trimester sonographic examination. J Clin Ultrasound 2000;28:307-310.

50. Wax JR, Grimes CK, Blackstone J, Pinette MG, Cartin A. Two- and three-dimensional prenatal sonographic diagnosis of hepatic cysts. J Clin Ultrasound 2009;37:96-99.

51. Leombroni M, Buca D, Celentano C, Liberati M, Bascietto F, Gustapane $S$, et al. Outcomes associated with fetal hepatobiliary cysts: systematic review and meta-analysis. Ultrasound Obstet Gynecol 2017;50:167-174.

52. Singh D, Kaur L, Kaur MP. Hepatic bubble: rare case of a primary hepatic cyst. J. Fetal Med 2017;4:203-205.

53. Shankar SR, Parelkar SV, Das SA, Mathure AB. An antenatallydiagnosed solitary, non-parasitic hepatic cyst with duodenal obstruction. Pediatr Surg Int 2000;16:214-215.

54. Okumura M, Liao AW, Brizot Mde L, Zugaib M, da Silva MM Sonographic detection of a giant solitary hepatic cyst in utero. J Ultrasound Med 2008;27:1663-1665.

55. Harris K, Carreon CK, Vohra N, Williamson A, Dolgin S, Rochelson B. Placental mesenchymal dysplasia with hepatic mesenchymal hamartoma: a case report and literature review. Fetal and Pediatric Pathology 2013;32:448-453.

56. Isaacs H Jr. Fetal and neonatal hepatic tumors. J Pediatr Surg 2007;42:1797-1803.

57. Makin E, Davenport M. Fetal and neonatal liver tumours. Early Hum Dev 2010;86:637-642

58. Khan MR, Binkovitz LA, Smyrk TC, Potter DD Jr, Furuya KN. Mesenchymal hamartoma in children: a diagnostic challenge. Case Rep Pediatr 2019:2019:4132842.

59. Woodward PJ, Sohaey R, Kennedy A, Koeller KK. From the archives of the AFIP: a comprehensive review of fetal tumors with pathologic correlation. Radiographics 2005;25:215-242.

60. Eickmeyer AB, Casanova NF, He C, Smith EA, Wan J, Bloom DA, et al. The natural history of the multicystic dysplastic kidney: is limited 
follow-up warranted? J Pediatr Urol 2014;10:655-661.

61. Khare A, Krishnappa V, Kumar D, Raina R. Neonatal renal cystic diseases. J Matern Fetal Neonatal Med 2018;31:2923-2929.

62. Cardona-Grau D, Kogan BA. Update on multicystic dysplastic kidney. Curr Urol Rep 2015;16:67.

63. van Eijk L, Cohen-Overbeek TE, den Hollander NS, Nijman JM, Wladimiroff JW. Unilateral multicystic dysplastic kidney: a combined pre- and postnatal assessment. Ultrasound Obstet Gynecol 2002;19:180-183.

64. Rabelo EA, Oliveira EA, Diniz JS, Silva JM, Filgueiras MT, Pezzuti IL, et al. Natural history of multicystic kidney conservatively managed: a prospective study. Pediatr Nephrol 2004;19:1102-1107.

65. Hains DS, Bates CM, Ingraham S, Schwaderer AL. Management and etiology of the unilateral multicystic dysplastic kidney: a review. Pediatr Nephrol 2009;24:233-241.

66. Rabelo EA, Oliveira EA, Silva GS, Pezzuti IL, Tatsuo ES. Predictive factors of ultrasonographic involution of prenatally detected multicystic dysplastic kidney. BJU Int 2005;95:868-871.

67. Yitta S, Saadai P, Filly RA. The fetal urinoma revisited. J Ultrasound Med 2014;33:161-166.

68. Adorisio O, Silveri M, Colajacomo M, Bassani F, Rivosecchi M. The impact of perinatal urinoma formation on renal function: our experience and review of the literature. J Paediatr Child Health 2011;47:217-222.

69. Stathopoulos L, Merrot T, Chaumoitre K, Bretelle F, Michel F, Alessandrini P. Prenatal urinoma related to ureteropelvic junction obstruction: poor prognosis of the affected kidney. Urology 2010;76:190-194.

70. Gorincour G, Rypens F, Toiviainen-Salo S, Grignon A, Lambert R, Audibert $F$, et al. Fetal urinoma: two new cases and a review of the literature. Ultrasound Obstet Gynecol 2006;28:848-852.

71. Maki E, Oh K, Rogers S, Sohaey R. Imaging and differential diagnosis of suprarenal masses in the fetus. J Ultrasound Med 2014;33:895-904.

72. Fernbach SK, Feinstein KA, Spencer K, Lindstrom CA. Ureteral duplication and its complications. Radiographics 1997;17:109-127.

73. Didier RA, Chow JS, Kwatra NS, Retik AB, Lebowitz RL. The duplicated collecting system of the urinary tract: embryology, imaging appearances and clinical considerations. Pediatr Radiol 2017;47:1526-1538.

74. Adeb M, Darge K, Dillman JR, Carr M, Epelman M. Magnetic resonance urography in evaluation of duplicated renal collecting systems. Magn Reson Imaging Clin N Am 2013;21:717-730.

75. Epelman M, Victoria T, Meyers KE, Chauvin N, Servaes S, Darge $K$. Postnatal imaging of neonates with prenatally diagnosed genitourinary abnormalities: a practical approach. Pediatr Radiol 2012;42 Suppl 1:S124-S141.

76. Castagnetti M, El-Ghoneimi A. Management of duplex system ureteroceles in neonates and infants. Nat Rev Urol 2009;6:307-
315.

77. Fisher JPH, Tweddle DA. Neonatal neuroblastoma. Semin Fetal Neonatal Med 2012;17:207-215.

78. Eo H, Kim JH, Jang KM, Yoo SY, Lim GY, Kim MJ, et al. Comparison of clinico-radiological features between congenital cystic neuroblastoma and neonatal adrenal hemorrhagic pseudocyst. Korean J Radiol 2011;12:52-58.

79. Liao YY, Chen HC, Chou CM, Lin YM. Antenatal detection of a congenital pancreatic cyst. J Formos Med Assoc 2003;102:273276.

80. Kebapci M, Aslan O, Kaya T, Ilhan H. Prenatal diagnosis of giant congenital pancreatic cyst of a neonate. AJR Am J Roentgenol 2000;175:1408-1410.

81. Gerscovich EO, Jacoby B, Field NT, Sanchez T, Wootton-Gorges SL, Saroufeem R. Fetal true pancreatic cysts. J Ultrasound Med 2012;31:811-813.

82. Fremond B, Poulain P, Odent S, Milon J, Treguier C, Babut JM. Prenatal detection of a congenital pancreatic cyst and BeckwithWiedemann syndrome. Prenat Diagn 1997;17:276-280.

83. Choi SJ, Kang MC, Kim YH, Lim JS, Lim SC, Chang JH. Prenatal detection of a congenital pancreatic cyst by ultrasound. J Korean Med Sci 2007;22:156-158.

84. Garza-Serna U, Ovalle-Chao C, Martinez D, Flores-Villalba E, DiazElizondo JA, Garza-Luna UJ. Laparoscopic partial splenectomy for congenital splenic cyst in a pediatric patient: Case report and review of literature. Int I Surg Case Rep 2017;33:44-47.

85. Sauvageot C, Faure JM, Mousty E, Flandrin A, Forgues D, Prodhomme 0 , et al. Prenatal and postnatal evolution of isolated fetal splenic cysts. Prenat Diagn 2018;38:390-394.

86. Sepulveda W, Ochoa JH, Cafici D, Wong AE, Badano F, Andreeva E, et al. Splenic cyst as a rare cause of fetal abdominal cystic mass: a multicenter series of nine cases and review of the literature. Ultrasound 2018;26:22-31.

87. Chen IL, Tsai CC, Yang SN, Liu CA, Hsu TY, Huang HC. Spontaneous regression of congenital splenic cyst in a neonate. Clin Pediatr (Phila) 2007;46:73-75.

88. Coulier B, Pierard F, Gielen I. Giant splenic epithelial congenital cyst. Diagn Interv Imaging 2020;101:57-58.

89. Koh CC, Wang NL, Lee HC, Duh YC. Infected congenital splenic cyst associated with duodenal duplication cyst and malrotation: a case report. J Pediatr Surg 2007;42:e21-e22.

90. Ray A, Kumari S. Congenital hydrocolpos: diagnostic journey and management: a case report. J Obstet Gynaecol India 2020;70:407408.

91. Murthy V, Costalez J, Weiner J, Voos K. Two neonates with congenital hydrocolpos. Case Rep Pediatr 2013;2013:692504.

92. Shaked O, Tepper R, Klein Z, Beyth Y. Hydrometrocolpos: diagnostic and therapeutic dilemmas. J Pediatr Adolesc Gynecol 2008;21:317321. 
93. Nakajima E, Ishigouoka T, Yoshida T, Sato T, Miyamoto T, Shirai M, et al. Prenatal diagnosis of congenital imperforate hymen with hydrocolpos. J Obstet Gynaecol 2015;35:311-313.

94. Hayashi S, Sago H, Kashima K, Kitano Y, Kuroda T, Honna T, et al. Prenatal diagnosis of fetal hydrometrocolpos secondary to a cloacal anomaly by magnetic resonance imaging. Ultrasound Obstet Gynecol 2005;26:577-579.

95. Danzer E, Hubbard AM, Hedrick HL, Johnson MP, Wilson $R D$, Howell LJ, et al. Diagnosis and characterization of fetal sacrococcygeal teratoma with prenatal MRI. AJR Am J Roentgenol 2006; 187:W350-W356.

96. Ho KO, Soundappan SV, Walker K, Badawi N. Sacrococcygeal teratoma: the 13-year experience of a tertiary paediatric centre. J
Paediatr Child Health 2011;47:287-291.

97. Avni FE, Guibaud L, Robert Y, Segers V, Ziereisen F, Delaet MH, et al. MR imaging of fetal sacrococcygeal teratoma: diagnosis and assessment. AJR Am J Roentgenol 2002;178:179-183.

98. Arisoy R, Erdogdu E, Kumru P, Demirci O, Ergin N, Pekin O, et al. Prenatal diagnosis and outcomes of fetal teratomas. J Clin Ultrasound 2016;44:118-125.

99. Gucciardo L, Uyttebroek A, De Wever I, Renard M, Claus F, Devlieger $R$, et al. Prenatal assessment and management of sacrococcygeal teratoma. Prenat Diagn 2011;31:678-688.

100. Hedrick HL, Flake AW, Crombleholme TM, Howell LJ, Johnson MP, Wilson RD, et al. Sacrococcygeal teratoma: prenatal assessment, fetal intervention, and outcome. J Pediatr Surg 2004;39:430-438. 